\title{
IN MOBILE WE TRUST: THE EFFECTS OF MOBILE VERSUS NON-MOBILE REVIEWS ON CONSUMER PURCHASE INTENTIONS
}

\author{
Lauren Grewal \\ Assistant Professor of Business Administration \\ Tuck School of Business, Dartmouth College \\ 100 Tuck Hall, Hanover, NH 03755, USA \\ Email: lauren.s.grewal@tuck.dartmouth.edu \\ Andrew T. Stephen \\ L’Oréal Professor of Marketing \& Associate Dean of Research \\ Saïd Business School, University of Oxford \\ Park End Street, OX1 1HP, UK \\ Email: andrew.stephen@sbs.ox.ac.uk
}

February 7, 2019

* Lauren Grewal is Assistant Professor of Business Administration, Tuck School of Business, Dartmouth College (lauren.s.grewal@tuck.dartmouth.edu). Andrew T. Stephen is L’Oréal Professor of Marketing and Associate Dean of Research, Saïd Business School, University of Oxford (andrew.stephen@sbs.ox.ac.uk). The authors thank the JMR review team for their helpful comments and suggestions throughout the review process. The authors additionally thank Dhruv Grewal, Yakov Bart, Juliano Laran, and Jeff Inman for feedback on this research. This research was funded by the Katz Graduate School of Business, University of Pittsburgh (where the first author was a doctoral student and the second author was a faculty member in the early days of this research) and the Oxford Future of Marketing Initiative at the Saïd Business School, University of Oxford. 


\section{IN MOBILE WE TRUST: THE EFFECTS OF MOBILE VERSUS NON-MOBILE REVIEWS ON CONSUMER PURCHASE INTENTIONS}

In the context of user-generated content (UGC), mobile devices have made it easier for consumers to review products and services in a timely manner. In practice, some UGC sites indicate if a review was posted from a mobile device. For example, TripAdvisor uses a "via mobile” label to denote reviews from mobile devices. However, the extent to which such information impacts consumers is unknown. To address this gap, the authors use TripAdvisor data and five experiments to examine how mobile devices impact consumers’ perceptions of UGC reviews and their purchase intentions. They find that knowing a review was posted from a mobile device can lead consumers to have higher purchase intentions. Interestingly, this is due to a process whereby consumers assume mobile reviews are more physically effortful to craft and subsequently equate this greater perceived effort with the credibility of the review.

Keywords: Mobile Marketing, Online Reviews, User-Generated Content, Word of Mouth 
The use of mobile devices is ubiquitous. Over half the world's population now uses mobile devices and over $52 \%$ of all website traffic worldwide is generated through mobile phones (Statista 2018). Given the overwhelming prevalence of mobile technology, understanding, broadly speaking, how mobile is impacting people's perceptions of the content they view online is an increasingly important research objective. However, despite the substantial proliferation of mobile devices, relatively little is known about the relationship between mobile devices and consumer behavior, and thus how managers can use mobile marketing to its full potential (Bart, Stephen, and Sarvary 2014; Fong, Fang, and Luo 2015; Grewal et al. 2016; Shankar et al. 2010).

A common use of mobile devices is creating user-generated content (UGC) and disseminating it through online platforms. This includes posts on social networks, sharing photos and videos through apps, and rating and reviewing products and services on online review sites. This latter type of UGC—ratings and reviews—is the focus of the current research. However, instead of considering differences that arise in the actual UGC that consumers produce based on whether its written on mobile devices or not (e.g., emotionality of UGC; Melumad, Inman, and Pham 2019; Ransbotham, Lurie, and Liu 2018), we consider how the knowledge that UGC was crafted on a mobile device impacts consumer attitudes and purchase intentions. This is practically relevant since on some popular platforms (e.g., TripAdvisor), consumers are explicitly made aware if a review was posted from a mobile device (e.g., with a "via mobile" icon adjacent to a review). Although this type of cue might seem innocuous, we find that this knowledge can positively influence consumers' evaluations of a UGC review. Specifically, we find that knowing a review was written on a mobile (vs. non-mobile) device—-holding the actual content of the review constant—can lead to higher purchase intentions. We show that this boost 
occurs because consumers think that mobile reviews require more physical effort to write, which in turn leads them to believe that the review is a more credible source of information due to a positive association between effort and credibility (i.e., the effort heuristic; Krueger et al. 2004). Accordingly, this greater perceived credibility results in a rise in consumers' purchase intentions for mobile, compared to non-mobile, reviews.

This research makes three main contributions to extant literature. First, we add to the literature on WOM and UGC. As there is only a recent exploration of the psychological processes that underlie the creation or evaluation of online WOM (for reviews see Lamberton and Stephen 2016 and Stephen 2016), we add to this literature by showing how the knowledge that online reviews were generated on mobile devices can positively impact consumer intentions. Second, we add to the growing body of research on mobile marketing (Bart, Stephen, and Sarvary 2014; Furner and Zinko 2017; Ghose, Goldfarb, and Han 2013; Luo et al. 2013; März, Schuback, and Schumann 2017; Ransbotham, Lurie, and Liu 2018), as well as the research on the consumer psychology of mobile devices in general (Melumad, Inman, and Pham 2019; Ward et al. 2017). Unlike prior work, which has mostly considered the nature of specific types of mobile content, the mobile search environment, and the effects of mobile advertising, the current research examines what consumers infer about information created on mobile devices, regardless of review text. Lastly, our research helps to address some of the conflicting findings in recent research into the impact of how mobile (vs. non-mobile) devices can influence consumers’ attitudes and behaviors. For a comprehensive summary of relevant mobile-related research in marketing and a comparison to the current research, see Table 1.

[INSERT TABLE 1 ABOUT HERE] 


\section{THEORETICAL BACKGROUND}

Previous research on online WOM has focused on various factors such as sales, diffusion, product demand, and more (e.g., Stephen and Galak 2012; Trusov, Bucklin, and Pauwels 2009; Villanueva, Yoo, and Hanssens 2008; also see review papers such as Berger (2014), Lamberton and Stephen (2016), and You, Vadakkepatt, and Joshi 2015). One form of UGC WOM is online reviews, as it is a very popular source of information for consumers. Online reviews influence product evaluations and sales (e.g., Chevalier and Mayzlin 2006; Tirunillai and Tellis 2012; for a review see Rosario et al. 2016) and, at the individual level, are important in consumer decision making (Zhu and Zhang 2010). For example, online reviews can positively influence consumers’ purchase intentions and willingness to pay for reviewed products and services (Ba and Pavlou 2002; Forman, Ghose, and Wiesenfeld 2008; Houser and Wooders 2006).

Critically, opinions expressed in online reviews by consumers are positioned as being more credible as they apparently reflect the apparently real opinions of people who have experienced the reviewed product or service (Bickart and Schindler 2001; Sher and Lee 2009). However, the extent to which another consumer's opinion is persuasive will invariably depend on many factors. Research has looked at some of the factors that positively influence the perceptions and persuasiveness of UGC, such as reviews that are newer or scarcer (Ludwig et al. 2013), considered less extreme (Cao, Duan, and Gan 2011; Mudambi and Schuff 2010), more readable (Ghose and Ipeirotis 2011), or longer (Pan and Zhang 2011).

In the extant UGC literature, however, a relatively unexplored factor is device type, i.e., the device on which a review was crafted (mobile vs. non-mobile). We argue that knowing that a 
review was written on a mobile device (e.g., as indicated by a "via mobile" label adjacent to the review) will positively influence a consumer's purchase intentions. We believe (and empirically show) that there's a link between the level of perceived physical effort needed to write a review on a mobile (vs. non-mobile) device, such that mobile is associated with greater effort. Consequentially, we suggest (and show) that when people think that writing a review on a mobile device requires greater physical effort, the review itself is perceived to be more credible. In turn, this greater perceived credibility results in the review being more influential. This conceptual framework is summarized in Figure 1.

\section{[INSERT FIGURE 1 ABOUT HERE]}

\section{What Makes User-generated Content More Persuasive?}

While UGC can positively impact attitudes and behavior, there has also been research suggesting that online reviews are sometimes manipulated (Mayzlin, Dover, and Chevalier 2014; Xiao and Benbasat 2011), which can increase consumer uncertainty (Zhao et al. 2013). Considering that consumers want to avoid manipulated or biased online reviews, an important aspect that affects whether consumers are persuaded or influenced by a reviewer's opinion is whether the review is deemed credible. Once a review is considered credible, the information contained within it is considered more valuable, is more often believed and accepted by the reader, and has been shown to affect attitudes behaviors (Cheung, Sia, and Kuan 2012; Chu and Kamal 2008; Smith and Vogt 1995; Zhang and Watts 2008). Therefore, any type of cue that could indicate a UGC review’s credibility could potentially influence a review’s persuasiveness.

Many cues might signal an online review’s credibility (e.g., written by an “expert” reviewer, the language used, and review length). However, one factor that has not been studied is consumer-perceived review writing effort. Effort (or perceived effort) has been correlated with 
how positively people perceive an outcome (e.g., effort expended in time, labor, pain, or money; Belk 1988; Festinger 1957; Moreau et al. 2011; Norton et al. 2012). For example, it has been shown that consumers reward firms that expend extra effort in the creation or display of their products, even when the actual product functions or outcomes do not differ (Morales 2005). Extant research has been mostly agnostic about the type of effort being expended (e.g., physical or mental effort), as typically, what matters is the belief that effort has been put into the object being evaluated. Importantly, this perceived effort has been associated with increased perceived quality and liking, which is referred to as the effort heuristic (Krueger et al. 2004). Applying the effort heuristic to our research context, we posit that consumers have an implicit belief that an online review that was perceived to be more effortful to write is more credible. This should then, in turn, positively influence purchase intentions for the reviewed product or service.

While multiple cues might influence perceived effort in the context of online reviews, we focus on the type of device on which the review was crafted as this cue is mostly unexplored and practically relevant. Following the information processing literature (e.g., Petty and Cacioppo 1981, 1986; Sundar 2007), we consider the indication of device type to be a peripheral cue that can positively influence consumer attitudes regarding the review. We believe that consumers may associate reviews written on mobile devices with greater levels of review-writing effort, since more physical effort is required to compose something clear and coherent on a mobile device than on a non-mobile device. We make this claim as prior studies have linked smartphone characteristics such as smaller device size, less visible screens, and smaller keyboards to increased physical and cognitive effort requirements when using a mobile device versus a nonmobile device (Chae and Kim 2004; Raptis et al. 2014; Sweeney and Crestani 2006). 
Taken together, we posit that consumers will think that UGC reviews written on mobile devices required more effort to produce and that this will trigger the effort heuristic. Consequently, knowing that a review was written on a mobile device is expected to lead to a higher perception of review credibility, which will result in that review being more persuasive. When and Why Mobile is Seen as a Positive Cue That Influences Decisions?

While we acknowledge that there are multiple indicators of effort or credibility that people can use to infer value in the context of online reviews, we focus on the cue of the device a review was written from. We only predict our process to occur however, if there are no other cues or provided information to contradict these assumptions. In a broad sense, our effect should only occur in situations where each component of our process is uninterrupted. As our process has multiple components, we suggest three managerially relevant moderators.

First, we do not expect our effect to occur when there may be other cues or available information that undermines the positive beliefs surrounding mobile reviews. This is relevant because heuristics are only influential if there is not competing information that consumers are motivated to process or are also weighing and considering (Shah and Oppenheimer 2008). Therefore, in situations where there is something that provides information about mobile reviews that contradict the ideas that mobile is effortful, we would not expect our effect. For example, if the review shows that it was low in effort to create (e.g., full of typos).

Second, in the same vein, we would not expect our results to occur when the attributes of mobile reviews (e.g., effortful to craft) are not judged in a positive light. Research has questioned the assumption that effort is a heuristic for quality (Kruger et al. 2004), such that there are scenarios where effort is linked to struggle and seen as a means to compensate, rather than indicating something positive about the quality of the outcome (e.g., lack of expertise; Schwarz 
2004). Therefore, if there are indicators that effort is not linked to quality or credibility, such as an external motivation for the review being written (e.g., compensation), we would not predict the positive effect of mobile as effort is no longer linked to credibility. Along similar lines, when there are other information cues or attributes present that more convincingly or strongly signal a review or reviewer's credibility (e.g., an explicit indicator of credible expertise), the reliance on a heuristic such as the effort heuristic is likely to be diminished.

Third, we propose that our effect occurs only for positive UGC reviews. Prior research has shown that consumers value negative information, and specifically, negative reviews, more than positive information and reviews (i.e., the negativity bias; Baumeister et al. 2001; Basuroy, Chatterjee, and Ravid 2003; Chen and Lurie 2013; Chevalier and Mayzlin 2006; Ito et al. 1998). This has been shown to occur as there are more repercussions to negative, rather than positive events (Baumeister et al. 2001). With negative reviews, as consumers are placing more weight on the information provided in the review, they are less likely to use heuristic cues (such as the mobile effort heuristic) as part of their decision-making process. With positive reviews on the other hand, this information is more attributed to the reviewer (Epley et al. 2004), and thus, cues that indicate that the reviewer put effort into their review and should be deemed credible—-such as the mobile cue-are more useful to consumers, and thus more likely to be utilized.

\section{Overview of Studies}

We test our conceptual framework using a combination of real-world data and experiments. Using TripAdvisor data, Study 1A tests whether reviews written on a mobile device impact how many “helpful” votes a review receives. Study 1B experimentally replicates Study 1A and introduces purchase intentions as a relevant dependent variable. Study 2A measures and manipulates perceived review writing effort while Study 2B manipulates perceived review 
writing effort and measures perceived review credibility. Study 3 manipulates and measures the perceived credibility of the review. Study 4 considers the boundary condition of review valence to our effect. Lastly, Study 5 re-examines the TripAdvisor data to show support for our hypothesized process. We summarize these findings in Table 2.

[INSERT TABLE 2 HERE]

\section{STUDY 1A}

Study 1A tests a central hypothesis in our conceptual framework-that reviews written on and posted from mobile devices are judged more favorably by consumers-using real-world data. For this we collected data from TripAdvisor, a travel-related review platform and the world's largest travel site. Importantly, for our purposes, for each review on TripAdvisor the site indicates if the review came from a mobile device with the label "via mobile” displayed on the review. Our data includes approximately 1.5 million UGC reviews for hotels in the twelve largest hotel markets in the US over three years. We find that reviews marked with the "via mobile” label have a significantly higher proportion of "helpful” votes, which we use as a proxy for TripAdvisor users’ favorable perceptions of those reviews and, more specifically, as indicators of higher perceived review credibility.

Data

Our dataset includes all publicly available online reviews on TripAdvisor.com posted between February 2012 and September 2015 for hotels located in the top 12 cities in the US by hotel room volume (e.g., Boston, Chicago, New York). Our data start in February 2012 because this is when the "via mobile" label was first observed. Our analysis is based on 1,547,219 
reviews for 2,379 hotels. Reviews in our data had ratings ranging from the lowest possible (1) to the highest possible (5). The mean rating was positive $(\mathrm{M}=4.06, \mathrm{SD}=1.07, \min =1, \max =5)$ and the majority of reviews were in the neutral $(3)$ or positive $(4,5)$ range $(90.59 \%$ above 2 and 76.42\% above 3). All reviews were used in the analysis reported below.

Importantly, for each review, we know whether the "via mobile” label was present or absent and the helpfulness rating (i.e., the number of times the review, at the time of data collection, had been voted as "helpful” by TripAdvisor users). We use these, respectively, as our independent and dependent variables. Additionally, we collected a number of other variables: (i) the rating given (1 to 5), (ii) hotel name and location, (iii) review date, headline, and full text, (iv) whether the hotel responded to the review, (v) whether the reviewer was recognized as a “Top Contributor” by TripAdvisor, (vi) the number of reviews the reviewer had written at the time data collection, and (vii) the number of helpful votes the reviewer had received across all their reviews at the time of data collection. Web Appendix A includes details of where these variables come from on a screenshot of a TripAdvisor review.

Analysis and Results

First, we looked for model-free evidence in support of our prediction that "via mobile” reviews should receive more helpfulness votes, on average, than reviews without this label. In this dataset of over 1.5 million reviews, only $6.89 \%$ of them had the "via mobile" label. Thus, if there is an effect of the presence of this label on the number of helpful votes received by reviews, it is likely to be small. This appeared to be the case. The average number of helpfulness votes received by a review without the "via mobile" label $(\mathrm{M}=.92, \mathrm{SD}=1.55)$ was slightly less than the average for reviews with the "via mobile" label $(\mathrm{M}=.94$, SD = 1.49). Removing outliers 
(number of helpfulness votes above the $99^{\text {th }}$ percentile) did not alter this pattern $\left(\mathrm{M}_{\text {mobile }}=.86\right.$, $\mathrm{SD}_{\text {mobile }}=1.19$ vs. $\left.\mathrm{M}_{\text {non-mobile }}=.83, \mathrm{SD}_{\text {non-mobile }}=1.18\right)$.

\section{[INSERT TABLE 3 ABOUT HERE]}

Next, we estimated a series of regressions to test our predictions (see Table 3). Since our dependent variable is measured as the number of helpful votes received for a review, we used a negative binomial regression model for count data to test the effect of the presence or absence of the “via mobile” label on helpfulness. We also controlled for certain review and reviewer characteristics as described above. The regression results are consistent with our prediction that the presence of the "via mobile” label is associated with a greater number of helpfulness votes.

In a base model without control variables the effect of mobile on helpfulness was positive and significant $\left(\mathrm{b}=.024, \chi^{2}=25.07, p<.001\right)$. Adding control variables related to review characteristics that could also conceivably affect helpfulness (rating, review length, whether the hotel responded) did not change this result $\left(b=.027, \chi^{2}=33.36, p<.001\right)$. Finally, we added additional controls for reviewer characteristics to account for reviewer heterogeneity since some reviewers might be better or more experienced than others, as this might affect helpfulness. For this we added covariates for the reviewer's mean helpfulness score and whether the reviewer was indicated as being a “Top Contributor.” After adding these controls for reviewer characteristics that might otherwise explain helpfulness, the effect of "via mobile” on helpfulness remained positive and significant $\left(\mathrm{b}=.020, \chi^{2}=24.15, p<.001\right)$. For robustness, we estimated Poisson and zero-inflated negative binomial models, each of which provided consistent results.

These results provide initial real-world support for our effect. A limitation of this study should, however, be acknowledged. These findings could be due to various alternative explanations, particularly given that there might be differences between mobile versus non- 
mobile reviews for the same hotel that drive perceived helpfulness (e.g., differences in the review text itself). We address this in the subsequent studies, which are randomized experiments where the review text is held constant and all that varies is the presence or absence of a "via mobile" label to indicate the device on which the review was written.

\section{STUDY 1B: EXPERIMENTAL REPLICATION OF TRIPADVISOR STUDY}

Study 1B conceptually replicates the finding from TripAdvisor. In this study, we capture this through perceived helpfulness of a review and purchase intentions for a reviewed hotel. Importantly, in this study (and all subsequent experimental studies), all participants viewed identical reviews where the only thing that varied was the device a review was written from. Method

Three hundred and sixty-nine members of Amazon Mechanical Turk (out of an initial 450) who passed attention checks (i.e., remembering the device the review was written on and review valence; see Web Appendix C for exact questions) participated in this survey for nominal payment $\left(\mathrm{M}_{\mathrm{age}}=36.07,48 \%\right.$ female $)$. Participants were randomly assigned to one of three conditions (mobile, non-mobile, control) in a between-subjects design.

Participants completed a "Hotel Review Task" (see Web Appendix D for the instructions). Specifically, we told participants that they would see and read a review taken from TripAdvisor for a hotel located in New Orleans, and afterwards answer some questions about it. In all three conditions, the same review was shown. This was an actual TripAdvisor review selected because it was emotionally neutral, moderately positive (4 out of 5 stars), and of a normal length. No reviewer information was provided, and the only difference between the 
conditions was the device label. Specifically, in the mobile condition, the label said, "via mobile,” identical to what appears on TripAdvisor. In the non-mobile condition, the label of "via desktop” was used to reduce ambiguity (which could otherwise confound this manipulation if there was no such label). In the control condition, there was no label to correspond to non-mobile reviews found in the real-world (see Figure 2 for review stimuli across studies).

\section{[INSERT FIGURE 2 ABOUT HERE]}

After reading the review, participants were asked to imagine that they were planning a visit to New Orleans and that they needed to stay at a hotel. We then asked them to indicate how much they would consider staying at this hotel $(1=$ not at all consider, $5=$ definitely would consider), and how helpful they found the review to be for choosing where to stay in New Orleans $(1=$ not at all helpful, 5 = very helpful). Finally, we asked our attention check questions and standard demographic questions.

\section{Results and Discussion}

Purchase intentions. A one-way between-subjects ANOVA was performed on purchase intentions as a function of device (mobile, non-mobile, control). The overall model was significant $(\mathrm{F}(2,366)=7.33, p=.001)$. We then conducted pairwise comparisons which revealed that, as predicted, participants who saw the "via mobile” label were more likely to consider staying at the hotel $(\mathrm{M}=3.70, \mathrm{SD}=.75)$ compared to those who saw the "via desktop" label $(\mathrm{M}=3.35, \mathrm{SD}=.82 ; \mathrm{F}=10.63, p=.001)$ or the control review $(\mathrm{M}=3.37, \mathrm{SD}=.87 ; \mathrm{F}=$ 11.36, $p=.001)$. There was no significant difference for those who saw the review in the nonmobile condition and control condition $(\mathrm{F}=.001, p=.915)$.

Helpfulness of the review. To conceptually replicate the findings from TripAdvisor in Study 1A, we ran the same ANOVA as in the previous analysis. The overall model was 
significant $(\mathrm{F}(2,366)=4.89, p=.008)$. Pairwise comparisons then revealed, as predicted, that participants who saw the "via mobile" label found the review more helpful $(\mathrm{M}=4.25, \mathrm{SD}=.68)$ compared to those who saw the "via desktop" label $(\mathrm{M}=3.93, \mathrm{SD}=.94 ; \mathrm{F}=9.30, p=.002)$ or the control review $(\mathrm{M}=4.02, \mathrm{SD}=.88 ; \mathrm{F}=4.58, p=.033)$. There was no significant difference for those who saw the review in the non-mobile and control conditions $(\mathrm{F}=.823, p=.365)$.

These findings are consistent with those in Study 1A, such that an indication that a review was written via mobile is more helpful and increases purchase intentions compared to the same review without a mobile label. As a follow up to this study, we ran another similar experiment, using a different category (i.e., restaurants; see Web Appendix E). Again, we found a positive effect of mobile on purchase intentions $(b=.44, t=2.10, p=.04)$.

\section{STUDY 2A}

In Study 2A, we consider the first link in our conceptual model—-the link from device to perceived effort. We do this by both manipulating and measuring the perceived effort that goes into a mobile, compared to non-mobile, review. Our prediction is that if participants are led to believe that there is no difference in the amount of effort required to write a review on a mobile versus a non-mobile device, then there will be no activation of the effort heuristic. This, in turn, means that there will not be a positive impact on purchase intentions due to mobile reviews.

\section{Method}

Four hundred and forty members of Prolific Academic (out of an initial 480) who passed attention checks completed this survey for nominal payment ( $\mathrm{M}_{\mathrm{age}}=31.18,42 \%$ female). 
Participants were randomly assigned to one of four conditions in a 2 (mobile, non-mobile) x 2 (effort attribution, control) between-subjects design.

All participants saw the same mobile and non-mobile reviews in the "Hotel Review Task.” To manipulate perceived review writing effort, participants in the effort attribution condition read about how the review had been composed. ${ }^{1}$ We informed them that, while it used to be difficult to engage with online review sites via mobile devices, these days the ease of writing and posting from a mobile device has been greatly improved and thus, mobile review writing is considered equally effortful to that of review writing from non-mobile devices (details in Web Appendix G). In the control conditions, this additional information was not provided.

Afterwards, participants indicated their purchase intentions (same as in Study 1B), and in randomized order, answered a number of scale items that tapped into perceived review writing effort (6 items; $\alpha=.85$; see Web Appendix $\mathrm{H}$ ), along with possible alternative explanations such as the overall comprehension of the review $(\alpha=.88)$, perceived reviewer spontaneity in review writing $(\alpha=.70)$, perceived reviewer similarity to the participant ( $\alpha=.88)$, perceived temporal distance of writing the review from the experience $(\alpha=.88)$, perceived expertise of the reviewer $(\alpha=.79)$, and perceived ulterior motives to writing the review ( $\alpha=.85$; alternative explanation items are listed in Web Appendix I). Lastly, participants answered the attention check and standard demographic questions.

\section{Results and Discussion}

Purchase intentions. We predicted that purchase intentions would be higher for the mobile (vs. non-mobile) review, but only when the effort heuristic of mobile was not interfered with (i.e., in the control condition). To test this, we regressed purchase intentions on device type

\footnotetext{
${ }^{1}$ A pre-test showed that mobile (vs. non-mobile) reviews are seen as more physically effortful $(\mathrm{b}=.35, \mathrm{t}=2.02, p=$ .045), but not more cognitively or emotionally effortful (both $p$ > .316; further information in Web Appendix F).
} 
(non-mobile $=-1$, mobile $=1$ ), effort attribution (control $=-1$, effort attribution $=1$ ), and their interaction. The overall model was significant $(\mathrm{F}(3,436)=6.328, p<.001)$. There was no main effect of device $(\mathrm{b}=.06, \mathrm{t}=1.35, p=.176)$, but there was a main effect of effort attribution $(\mathrm{b}=$ $-.14, \mathrm{t}=-3.33, p<.001)$. The interaction effect of device type and attribution condition was significant $(\mathrm{b}=-.100, \mathrm{t}=-2.36, p=.019)$.

Importantly, the simple effect of mobile on purchase intentions was positive and significant in the control condition $(\mathrm{b}=.157, \mathrm{t}=2.46, p=.015)$, such that those who saw a mobile review had a higher purchase intention $(\mathrm{M}=3.59$, SD $=.884)$ than those who believed the review was written on a desktop computer $(\mathrm{M}=3.28, \mathrm{SD}=1.03)$. The simple effect of mobile was not significant in the effort attribution condition, i.e., when participants believed there was equal effort put into the review regardless of device $(\mathrm{b}=-.042, \mathrm{t}=-.769, p=.443$; $\mathrm{M}_{\text {mobile }}=3.11, \mathrm{SD}_{\text {mobile }}=.760$ vs. $\left.\mathrm{M}_{\text {non-mobile }}=3.20, \mathrm{SD}_{\text {non-mobile }}=.861\right)$.

Moderated mediation analysis. To examine whether effort plays a mediating role in the relationship between device and purchase intentions, a moderated mediation model was estimated using PROCESS Model 8 (Hayes 2017). We observed a significant index of moderated mediation $\left(\mathrm{b}=-.09\right.$, se $\left.=.03, \mathrm{CI}_{95}[-.17,-.04]\right)$ and the conditional indirect effect of mobile on purchase intentions, through perceived effort, was positive and significant in the control condition $\left(\mathrm{b}=.06\right.$, se $\left.=.02, \mathrm{CI}_{95}[.01, .11]\right)$, but negative and significant in the effort attribution condition $\left(\mathrm{b}=-.04\right.$, se $=.02, \mathrm{CI}_{95}[-.08,-.004]$; see Table 4).

\section{[INSERT TABLE 4 ABOUT HERE]}

Alternative Explanations. We ran regressions on several alternative explanations (all mentioned in the methodology section). Running the regressions by device type (non-mobile = 1 , mobile $=1$ ), effort attribution condition (control $=-1$, effort attribution $=1$ ), and their 
interaction, we found no significant interaction effects on any of these alternative explanation items (all $p>.16$ ). We additionally found no main effects of device (all $p>.17$ ) or effort attribution (all $p>.08$ ), nor did we find moderated mediation (all CI95 included 0). ${ }^{2}$

Study 2A, by manipulating and measuring perceived review writing effort, demonstrates that differences in purchase intentions between mobile (and non-mobile reviews) only occurs when the effort heuristic surrounding mobile reviews is not interfered with.

\section{STUDY 2B}

In Study 2B, we manipulate the perceived review writing effort and measure perceived review credibility of reviews. We predict that in the control condition that mobile (vs. nonmobile) reviews will raise the perceived review credibility and subsequent purchase intentions, while this effect will be attenuated when the effort heuristic surrounding mobile is interfered with, as when there is no link between mobile and effort, there should no longer be a connection between mobile and perceived credibility.

\section{Method}

Two hundred and twelve undergraduate students at a large university in the United States completed this survey as part of a session of multiple unrelated studies and were compensated with course credit $\left(M_{a g e}=20.49,50 \%\right.$ female). Students were randomly assigned to one of four conditions in a 2 (mobile, non-mobile) x 2 (effort attribution, control) between-subjects design. Participants who did not pass the same attention checks used in previous studies were dropped, which left us with data from 182 participants.

\footnotetext{
${ }^{2}$ Including all the proposed mediators in a single mediation analysis, we find that only effort mediates $(\mathrm{b}=-.10$, se $=$ .04 CI $\left._{95}[-.18,-.04]\right)$. All other mediators include 0 in the 95\% CI.
} 
Participants engaged in the same "Hotel Review Task" as in Study 2A. After this, participants were asked the same purchase intention question for the reviewed hotel and were asked about the perceived credibility of the review (6 items; $\alpha=.88$; see Web Appendix J). Lastly, participants answered attention check and standard demographic questions.

\section{Results and Discussion}

We predicted that purchase intentions would be higher for the mobile review than for the non-mobile review, but only when the effort heuristic of mobile was not interfered with (i.e., in the control condition). To test this, we regressed purchase intentions on device type (non-mobile $=-1$, mobile $=1$ ), effort attribution (control = -1 , effort attribution $=1$ ), and their interaction.

The overall model was significant $(F(3,178)=5.99, p<.001)$. There was no main effect of device $(\mathrm{b}=.04, \mathrm{t}=.749, p=.455)$, but there was a main effect of effort attribution $(\mathrm{b}=-.14, \mathrm{t}$ $=-2.47, p=.014)$. The interaction effect of device type and attribution condition was significant $(\mathrm{b}=-.158, \mathrm{t}=-2.76, p=.006)$. Importantly, the simple effect of mobile on purchase intentions was positive and significant in the control condition $(\mathrm{b}=.20, \mathrm{t}=2.40, p=.019)$, such that those who saw a mobile review had a higher purchase intention $(\mathrm{M}=3.58, \mathrm{SD}=.875)$ than those who believed the review was written on a desktop computer $(\mathrm{M}=3.18, \mathrm{SD}=.683)$. The simple effect of mobile was not significant in the effort attribution condition, i.e., when participants believed there was equal effort put into the review regardless of device, $(\mathrm{b}=-.12$, $\mathrm{t}=-1.28, p=.168$; $\mathrm{M}_{\text {mobile }}=2.98, \mathrm{SD}_{\text {mobile }}=.733$ vs. $\left.\mathrm{M}_{\text {non-mobile }}=3.21, \mathrm{SD}_{\text {non-mobile }}=.650\right)$.

Moderated mediation analysis. To examine whether perceived review credibility plays a mediating role in the relationship between device type and purchase intentions, and to determine whether perceived review writing effort influences review credibility, a moderated mediation model was estimated using PROCESS Model 8 (Hayes 2017). This model specifies that the path 
from device type to perceived review-credibility is moderated by the effort attribution condition, and that perceived credibility then influences purchase intentions. We observed a significant index of moderated mediation $\left(\mathrm{b}=-.18\right.$, se $\left.=.06, \mathrm{CI}_{95}[-.33,-.07]\right)$ and the conditional indirect effect of mobile on purchase intentions, through perceived credibility, is positive and significant in the control condition $\left(\mathrm{b}=.15\right.$, se $\left.=.05, \mathrm{CI}_{95}[.07, .27]\right)$ but not significant in the effort attribution condition $\left(\mathrm{b}=-.02\right.$, se $=.04, \mathrm{CI}_{95}[-.10, .05]$; see Table 4$)$.

Study 2B demonstrates that a belief that writing reviews from mobile devices is effortful is necessary for mobile to increase perceived review credibility, and subsequent purchase intent for a reviewed product or service. When participants' belief about review writing effort was interfered with, mobile was no longer effective at increasing purchase intentions.

This study, in addition to providing process evidence of our conceptual framework, also serves two other purposes. The first is that, in this study, as we did not measure effort beliefs, yet still found that mobile influenced review credibility and consequent purchase intentions, we can feel more assured that our effects are not due to self-generated validity (Feldman and Lynch 1988). Second, this study highlights that effort is integral to the effect we find. Mobile reviews increase purchase intentions because of their perceived effort and subsequent perceived credibility; this is not a story about credibility without effort, which rules out alternative explanations that are based in other rationales for why mobile may be seen as credible.

\section{STUDY 3}

In Study 3, we manipulate the second link in our conceptual model—review writing effort to perceived credibility. We do this by manipulating the perceived motivation of the 
review, thus compromising the credibility of the review, and consequently, diminishing the positive impact of mobile devices on purchase intentions. Thus, this study both manipulates and measures review credibility in addition to measuring perceived review writing effort.

\section{Method}

Three hundred and ninety-four members of Amazon Mechanical Turk (out of an initial 420) passed attention checks and completed this survey for nominal payment $\left(\mathrm{M}_{\mathrm{age}}=35,43 \%\right.$ female). Participants were randomly assigned to one of four conditions in a 2 (mobile, nonmobile) x 2 (external motivation, control) between-subjects design.

The procedure began as it did in previous studies using the "Hotel Review Task” but with a different review to what was used previously (see Figure 2). To manipulate the reviewer’s motivation, reviews in the external motivation condition were labeled as being "collected in partnership with the hotel” while those in the control condition contained no additional information. This language came directly from TripAdvisor to enhance realism and was shown to make people believe the review was written due to reviewer compensation $(p<.001)$.

After this, participants were asked to consider that they were planning a visit to Boston and needed to find a hotel. Participants then answered the same purchase intention question as in previous studies and, in randomized order, answered items about the perceived review-writing effort (same items as in Study 2A; $\alpha=.90$ ), and on the perceived credibility of the review (same items as in Study 2B; $\alpha=.89$ ). Lastly, participants wrote about why they believed the reviewer wrote their review and answered attention check questions and standard demographic questions.

Afterwards, we contacted a separate sample of participants to code the open responses. Using only the initial readers' rationale for why a review was written, three coders read each open response (inter rater reliability $=.86$ ) that indicated beliefs regarding reviewer motivations 
to determine possible underlying beliefs about mobile and non-mobile written-reviews (the findings from this analysis are included in Web Appendix K).

\section{Results and Discussion}

Purchase intentions. We predicted that purchase intentions would be higher for the mobile (vs. non-mobile) review, however only in the control condition. To test this, we regressed purchase intentions on device type (non-mobile $=-1$, mobile $=1$ ), motivation $($ control $=-1$, external $=1)$, and their interaction. The overall model was significant $(\mathrm{F}(3,394)=7.58, p<$ $.001)$. There were main effects of both device type $(\mathrm{b}=.09, \mathrm{t}=2.27, p=.024)$ and motivation (b $=-.30, \mathrm{t}=-3.94, p<.001)$. The interaction was also significant $(\mathrm{b}=.33, \mathrm{t}=2.06, p=.04)$.

Importantly, the simple effect of mobile device on purchase intentions was positive and significant in the control condition when there was no information provided information on the reviewer's possible motivation $(\mathrm{b}=.142, \mathrm{t}=2.76, p=.006)$, such that those who saw a mobile review had a higher purchase intention $(\mathrm{M}=4.16, \mathrm{SD}=.587)$ than those who believed the review was written on a desktop computer $(\mathrm{M}=3.88, \mathrm{SD}=.836)$. As expected, due to interference with the hypothesized process, the simple effect of mobile device was not significant when there was an external motivation to the review $\left(\mathrm{b}=.033, \mathrm{t}=.585, p=.560 ; \mathrm{M}_{\text {mobile }}=3.75\right.$, $\mathrm{SD}_{\text {mobile }}=.842$ vs. $\left.\mathrm{M}_{\text {non-mobile }}=3.67, \mathrm{SD}_{\text {non-mobile }}=.750\right)$.

Serial Moderated Mediation. We then tested the complete mechanism (i.e., mobile $\rightarrow$ effort $\rightarrow$ credibility $\rightarrow$ purchase intentions; see Figure 3). We expected that the indirect effect of mobile on purchase intentions would be positive and significant, through this mechanism, in the control condition but not when there was external motivation to write the review. As we predicted that review writing motivation would specifically influence perceived review credibility (i.e., our second mediator), we ran a serial moderated mediation model which places 
the moderator on the link between the first mediator (i.e., review writing effort) and the second mediator (i.e., review credibility; Hayes 2017, PROCESS Model 91).

We observed a significant index of moderated mediation $\left(\mathrm{b}=.07\right.$, se $=.04, \mathrm{CI}_{95}[.01$, .15]). We found that the conditional indirect effect of mobile on purchase intentions, through perceived review writing effort and then perceived review credibility, is positive and significant in the control condition $\left(\mathrm{b}=.09\right.$, se $\left.=.03, \mathrm{CI}_{95}[.04, .16]\right)$ but not significant when there is an external motivation prompting the review $\left(\mathrm{b}=.02\right.$, se $=.01, \mathrm{CI}_{95}[-.01, .05]$; see Web Appendix L for a robustness check and Web Appendix M for the corresponding mediation table).

\section{[INSERT FIGURE 3 HERE]}

In Study 3, we find that when there are indications that a review was written due to some external motivation, mobile reviews do not positively impact purchase intentions. This occurs because, despite the link between mobile and perceived review writing effort, when perceived effort is no longer linked to credibility (e.g., through a compensated review), mobile is less persuasive in consumers’ purchase decisions. Additionally, the results of the extra analysis of coded responses for reviewer motivation provides some support that there is not a lay theory regarding the motivations for posting reviews from mobile (compared to non-mobile) devices.

\section{STUDY 4}

Study 4 examines the final link in our conceptual model—credibility to purchase intentions - by examining a boundary condition of review valence. We predict that mobile reviews will only influence purchase intentions for positive, but not negative, reviews. This is because the heuristic cue of "mobile as effortful and, consequently, credible” should be more 
often utilized when the information contained in the review is deemed less consequential and information is attributed more to the reviewer themselves (i.e., for positive rather than negative information; e.g., Baumeister et al. 2001; Epley et al. 2004).

Method

Four hundred and fourteen members of Turk Prime’s sample pool (out of an initial 500) who passed attention checks participated in this survey for nominal payment $\left(\mathrm{M}_{\mathrm{age}}=43.89,56 \%\right.$ female). These participants are distinct from Mechanical Turk Workers (only 2\% were on both platforms) and are more naïve to behavioral studies. Participants were randomly assigned to a condition in a 2 (mobile, non-mobile) x 2 (positive, negative) between-subjects design.

All participants saw the same "Hotel Review Task" used in Studies 1B, 2A and 2B. In the negative condition, the hotel was rated 2 stars while in the positive condition the same review gave the hotel 4 stars (see Figure 2). The review text was sufficiently balanced and could plausibly be either a 2- or 4-star review. Following this, in randomized order, participants indicated their purchase intention (same as prior studies), review helpfulness (same as in Study 1B), the perceived effort of review writing ( $\alpha=.87$; same as prior studies), and other possible explanations (same as in Study 2A). In this study, we consider review helpfulness as a proxy for review credibility (same as in the real-world data from TripAdvisor). Lastly, participants were asked our standard attention check questions and demographic questions.

\section{Results and Discussion}

Purchase intentions. We predicted that purchase intention would be higher for the mobile review than the non-mobile review, however only when the review was positive. To test this, we regressed purchase intentions on device type (non-mobile $=-1$, mobile $=1$ ), valence $($ negative $=$ -1 , positive $=1$ ), and their interaction. 
The overall model was significant $(\mathrm{F}(3,411)=43.61, p<.001)$ and the main effects of device and valence were both significant (device: $\mathrm{b}=.305, t=6.72, p<.001$; valence: $\mathrm{b}=.364, t$ $=8.01, p<.001)$. The interaction of device type and valence was also significant, as expected (b $=.22, \mathrm{t}=4.80, p<.001)$. Simple effects of mobile on purchase intentions were as hypothesized. When the review was positive, those who saw a mobile review had higher purchase intentions $(\mathrm{M}=3.70, \mathrm{SD}=.99)$ than those who believed the review was written on a computer $(\mathrm{M}=2.65$, $\mathrm{SD}=.95 ; \mathrm{b}=.52, \mathrm{t}=7.98, p<.001)$. When the review was negative, the effect of mobile on purchase intentions was not significant $\left(\mathrm{b}=.09, \mathrm{t}=1.40, p=.162 ; \mathrm{M}_{\text {mobile }}=2.54, \mathrm{SD}_{\text {mobile }}=.91\right.$ vs. $\mathrm{M}_{\text {non-mobile }}=2.36, \mathrm{SD}_{\text {non-mobile }}=.83$ ).

Serial Mediated Moderation. We then tested the complete mechanism (i.e., mobile $\rightarrow$ effort $\rightarrow$ credibility $\rightarrow$ purchase intentions; see Figure 3). We expected the indirect effect of mobile on purchase intentions to be positive and significant, through this mechanism, only when the review was positive. To test our full serial mediation process, we ran a serial moderated mediation model which places the moderator on the links between the independent variable and dependent variable along with on the links from the first mediator (i.e., review writing effort) and the second mediator (i.e., review credibility; Hayes 2017, PROCESS Model 89).

We observed a significant index of moderated mediation $\left(\mathrm{b}=.03\right.$, se $=.01, \mathrm{CI}_{95}[.01$, .06]). Specifically, we found that the conditional indirect effect of mobile on purchase intentions, through perceived review writing effort and then credibility, is positive and significant for positive reviews $\left(\mathrm{b}=.03\right.$, se $\left.=.009, \mathrm{CI}_{95}[.01, .05]\right)$ but not significant for negative reviews $(\mathrm{b}=$ .002 , se $=.008, \mathrm{CI}_{95}[-.01, .02]$; see Web Appendix L for a robustness check and Web Appendix M for the corresponding mediation table). 
Alternative Explanations. We ran regressions on several alternative explanations (all mentioned in the methodology section). Running the regressions by device type (non-mobile = 1 , mobile $=1$ ), valence (negative $=-1$, positive $=1$ ), and their interaction on these different items, we found no significant interaction effects of device type and valence on these items (all $p$ $>$.06). We additionally found no main effects of device (all $p>.07$ ) or valence (all $p>.17$ ). Lastly, when conducting mediated moderation where these variables were tested as the primary mediator (both in a parallel mediation analysis and in separate mediation analyses), we found that none of these significantly mediated the relationship between device and purchase intentions (all CI95 included 0; Hayes 2017, PROCESS Model 15).

Study 4 demonstrates that consumers have a belief that writing reviews from mobile devices is more effortful than from non-mobile devices (regardless of review valence). However, despite the perceived effort of writing and the perceived credibility of mobile reviews existing across positive and negative valences, only positive mobile reviews impact purchase intentions. We believe this to be the case as the perceived effort and credibility of a review only impacts a consumer if they are still willing to consider a product or service.

\section{STUDY 5}

In this final study, we revisit the TripAdvisor data used in Study 1A to establish some corroborating real-world evidence in support of the process-related findings reported in our experimental studies.

Perceived Effort and Credibility 
In previous studies, the theoretically important roles of perceived review-writing effort and review credibility were established. The reason, we argued, as to why the innocuous "via mobile” indicator on a review might lead to higher perceived review helpfulness and, subsequently, higher purchase intent is based on the activation of the effort heuristic. One way to demonstrate this using TripAdvisor data is to consider other review or reviewer characteristics whose presence would signal review credibility or quality, acting as surrogates for the effort heuristic, and interfering with the mobile-related activation of the effort heuristic. When there are multiple cues that consumes can attend to, the effort heuristic based on the "via mobile" cue would simply not be needed as its added benefit would be attenuated in the presence of other indicators of effort, review quality, or credibility. We examined this in a number of ways.

First, we considered the “Top Contributor” indicator. This is a reviewer characteristic that could signal credibility, and consequently, obviate the need for a mobile-related effort heuristic. We tested this by estimating the same negative binomial regression as before (i.e., including control variables) and adding an interaction between the "Top Contributor" and "via mobile" variables. Consistent with our logic, the interaction was significant and negative $\left(b=-.052, \chi^{2}=\right.$ 25.69, $p<.001$ ). When the review was not written by a "Top Contributor" (akin to a control condition where there was nothing to interfere with the activation of the effort heuristic), the mobile effect was positive $\left(b=.031, \chi^{2}=44.92, p<.001\right)$. However, when the review was written by a “Top Contributor,” and thus there was another cue present to signal credibility, the effect of mobile was not positive $\left(b=-.021, \chi^{2}=5.12, p=.024\right)$. In this analysis, as expected if it interferes with the mobile effect when the indicator is present, the effect of "Top Contributor" on helpfulness was significant and positive $\left(\mathrm{b}=.082, \chi^{2}=865.18, p<.001\right)$. 
Second, we considered review length as a moderator. If a review is longer, presumably the effort a reviewer went to does not need to be inferred peripherally from a cue such as the "via mobile” label. If so, we would expect the mobile effect on helpfulness to be attenuated for longer reviews. The logic is the same as for the "Top Contributor" analysis; i.e., if the "via mobile” label triggers the effort heuristic, the presence of this cue should be less influential when there are other, more direct indicators of reviewer effort available. The results were consistent with our expectations. The interaction between review length and the mobile indicator was significant and negative ( $\left.\mathrm{b}=-.0001, \chi^{2}=16.38, p<.001\right)$. The effect of mobile on helpfulness when review length was average $(M=391.23$ characters, $S D=211.84)$ was positive and significant $(b=.202$, $\left.\chi^{2}=23.87, p<.001\right)$. Similarly, the effect was positive and significant when review length was shorter (1 SD below mean length; $\mathrm{b}=.037, \chi^{2}=40.31, p<.001$ ), as expected. Conversely, when review length was longer there was no effect of "via mobile” on helpfulness (1 SD above mean length; $\left.\mathrm{b}=.003, \chi^{2}=.34, p=.559\right)$. In addition to this spotlight analysis, we conducted a floodlight analysis using values within the range of review lengths observed in our data. The Johnson-Neyman point was a review length of 524 characters, meaning that the mobile effect was not significant $(p>.05)$ when review length was greater than 524 characters. It was positive and significant below this. In these analyses, as we expected, the effect of review length on helpfulness was significant and positive $\left(b=.0003, \chi^{2}=4,351.36, p<.001\right)$.

Finally, we considered the reviewer's mean helpfulness score as a potential moderator. Unlike the “Top Contributor” label and review length, this is not observable to users. Following our previous arguments, the positive effect of mobile on helpfulness should be attenuated when other cues are present that provide more-direct indicators of credibility. That being the case, something unobservable should not interfere with the mobile effect. We tested this by estimating 
the same negative binomial regression and adding an interaction between mobile and the reviewer's mean helpfulness score. As expected, the interaction was not significant $\left(b=-.005, \chi^{2}\right.$ $=2.10, p=.147$ ), which is consistent with our argument. This provides additional support for our theory that the effect of device type is about the activation of the mobile-based effort heuristic and that it is not driven by, for instance, other kinds of reviewer or review characteristics.

\section{Review Valence}

Study 4 found a moderating role of valence, such that the positive effect of mobile on purchase intentions only occurred for positive reviews. Given that we show how this effect occurs through perceived reviewer effort and review credibility, it should be the case that a proxy for review credibility in our TripAdvisor data_-helpfulness—is differentially affected by mobile device depending on valence. Using the review rating (1-5), we tested this. We estimated negative binomial regressions as in Study 1A, with the same control variables, and with the number of "helpful" votes received as the dependent variable and the presence of the "via mobile” label as the independent variable. Additionally, we added an interaction between "via mobile” and review rating to test the moderating role of review valence.

Consistent with Study 4, the interaction between "via mobile” and review rating was positive and significant $\left(\mathrm{b}=.013, \chi^{2}=13.14, p<.001\right)$. A floodlight analysis revealed that, as rating increases, the effect of the "via mobile" indicator on helpfulness goes from non-significant to positive and significant. When ratings are negative (1 and 2$)$, the mobile effect is nonsignificant (rating $=1: \mathrm{b}=-.017, \chi^{2}=2.28, p=.131$; rating $=2: \mathrm{b}=-.004, \chi^{2}=.25, p=.620$ ). When the rating is neutral (3), the mobile effect is marginally significant and positive $(b=.009$, $\chi^{2}=2.83, p=.092$ ). And when ratings are positive (4 and 5), the mobile effect is significant and 
positive (rating $=4: \mathrm{b}=.022, \chi^{2}=26.86, p<.001$; rating $\left.=5: \mathrm{b}=.034, \chi^{2}=36.94, p<.001\right){ }^{3}$

Thus, we find in real-world TripAdvisor data evidence corroborating the finding in Study 4 that the effect of mobile occurs only for positive reviews.

\section{Discussion}

In this study, we revisited the TripAdvisor data from Study 1A to test potential theoryrelated moderators present in the data as review and reviewer characteristics. We found realworld evidence consistent with the findings from our experimental studies related to effort, credibility, and valence boundary conditions for the mobile effect.

\section{GENERAL DISCUSSION}

Given the rising impact of mobile devices and the ever-important role of UGC and WOM in consumer decision-making, it is necessary to understand consumers’ interferences and biases related to device type when processing UGC reviews. Across our studies and real-world data, we found that when consumers read a review posted from a mobile device, important interferences are made. First, consumers believe that writing mobile (vs. non-mobile) reviews require more physical effort. Second, because of this perceived effort, consumers find that review more credible due to the triggering of the effort heuristic. Finally, because of this perceived effort and credibility, the review is more persuasive in influencing purchase. Importantly, this pattern only holds when the review is positive and the beliefs surrounding this process are not interrupted or interfered with by the presence of other pieces of information that are more easily accessible indicators of review effort or credibility. Following recent calls (McShane and Böckenholt

\footnotetext{
${ }^{3}$ The difference in the simple effects of mobile on helpfulness when the rating is positive (4 or 5 ) is not significant, as the $95 \%$ Wald confidence intervals for the parameters overlap.
} 
2017), we conducted a single-paper meta-analysis (SPM) of the experimental studies in this paper where we found the across-study estimate of the effect of mobile on purchase intentions is .47 (95\% CI: .21 - .77), indicating that mobile (vs. non-mobile) reviews positively influenced purchase intentions (see Web Appendix N for further detail on the SPM and for results found using meta analytic techniques from Rosenthal and Rosnow 2008).

Our research makes several contributions to the literatures on online WOM, UGC, and mobile marketing. This work follows recent calls for more research that examines mobile devices and how they influence consumer behavior (Grewal et al. 2016; Lamberton and Stephen 2016; Stephen 2016). As well, while recent work has considered actual differences that exist for mobile (vs. non-mobile) reviews, no work to date has focused on the inferences consumers make about mobile reviews—-while holding review content constant. Importantly, by holding the review text constant, we are able to isolate inferences surrounding "mobile," rather than examining outcomes of mobile reviews that then subsequently influence consumers which may contribute to the conflicting nature of recent mobile research that finds mobile reviews positively and negatively impact behavior and evaluation (e.g., Furner and Zinko 2017; März, Schuback, and Schumann 2017; Ransbotham, Lurie, and Liu 2018).

\section{Future Research}

There are many avenues for future research that stem from the current work. One implication of our research is that seemingly innocuous contextual factors can be persuasive. While we considered one mobile-related factor, there likely exist many others. To investigate some of these inferences that consumers hold about mobile reviews, we ran a follow-up study that examined consumer responses to content written on computers compared to mobile. 
Participants ( $\mathrm{n}=211, \mathrm{M}_{\mathrm{age}}=20.27,45 \%$ female) thought about online reviews and wrote about when and why someone may write reviews using a mobile or non-mobile device. These open responses were then coded by another sample (ICC $=.85$ ). While we found that a large percentage of our sample organically discussed review writing effort (92\%), and specifically that mobile is more physically effortful (77.5\%), supporting our findings across studies, other inferences also existed (e.g., mobile reviews were seen as more emotional [27\%] or spontaneous [63.6\%]). Considering these results, there may be instances where readers of UGC may have different inferences surrounding mobile reviews that subsequently influence their beliefs and behaviors. While we did not see other types of inferences surrounding mobile reviews influence our results where the text was held constant (e.g., spontaneity, recency of review, etc.), future research can address when different inferences about mobile are more or less salient and important in a consumer’s decision-making process.

Additionally, our findings may offer a new perspective on which to explore the negativity bias in online reviews (Basuroy, Chatterjee, and Ravid 2003; Chen and Lurie 2013; Chevalier and Mayzlin 2006). In our studies, we found that the mobile-triggered effort heuristic only impacted purchase and helpfulness for reviews that were positive. This finding suggests that some of the debate that surrounds review valence bias may be due to what information surrounding reviews themselves that consumers choose to focus on when considering online reviews. The effect of heuristic cues in relation to valence and helpfulness has not yet been discussed extensively in prior research and is an interesting avenue for future research.

Another direction for future research is to look at how creating mobile UGC across different types of online platforms other than online review sites. While we focused on the context of online review sites in this research, consumers are using their mobile devices across 
many types of platforms (e.g., social media). As there is a burgeoning body of research that focuses on the individual-level consequences of social media use (e.g., Grewal, Stephen, and Coleman 2019; John et al. 2017; Wilcox and Stephen 2013; and Zhang et al. 2017), future research could address how creating (or reading) UGC on mobile phones is changing the way consumers subsequently feel and behave across many different types of social media UGC (e.g., tweets on Twitter, Instagram posts).

In conclusion, our results demonstrate that mobile devices can impact the ways that consumers not only interact with online content, but how they interpret what other consumers say. As UGC review platforms continue to flourish and make their sites more amenable to mobile users, understanding how these actions impact not only users of mobile, but readers of mobile content, is increasingly important. We hope that this research encourages more studies into the ways mobile devices are impacting consumers psychologically and behaviorally online. 


\section{REFERENCES}

Ba, Sulin, and Paul A. Pavlou (2002), "Evidence of the Effect of Trust Building Technology in Electronic Markets: Price Premiums and Buyer Behavior,” MIS Quarterly, 26 (3), 243268.

Babić Rosario, Ana, Francesca Sotgiu, Kristine De Valck, and Tammo HA Bijmolt (2016), "The Effect of Electronic Word of Mouth on Sales: A Meta-analytic Review of Platform, Product, and Metric Factors,” Journal of Marketing Research, 3 (53), 297-318.

Bart, Yakov, Andrew T. Stephen, and Miklos Sarvary (2014), "Which Products are Best Suited to Mobile Advertising? A Field Study of Mobile Display Advertising Effects on Consumer Attitudes and Intentions,” Journal of Marketing Research, 51 (3), 270-285.

Baumeister, Roy F., Ellen Bratslavsky, Catrin Finkenauer, and Kathleen D. Vohs (2001), "Bad Is Stronger Than Good,” Review of General Psychology, 5 (4), 323-70.

Basuroy, Suman, Subimal Chatterjee, and S. Abraham Ravid (2003), "How Critical Are Critical Reviews? The Box Office Effects of Film Critics, Star Power, and Budgets,” Journal of Marketing, 67 (4), 103-17.

Belk, Russell W (1988), "Possessions and the Extended Self,” Journal of Consumer Research, 15 (2), 139-168.

Berger, Jonah (2014), "Word of Mouth and Interpersonal Communication: A Review and Directions for Future Research,” Journal of Consumer Psychology, 24 (4), 586-607.

Bickart, Barbara, and Robert M. Schindler (2001), "Internet Forums as Influential Sources of Consumer Information," Journal of Interactive Marketing, 15 (3), 31-40.

Cao, Qing, Wenjing Duan, and Qiwei Gan (2011), "Exploring Determinants of Voting for the "Helpfulness" of Online User Reviews: A Text Mining Approach," Decision Support Systems, 50 (2), 511-521.

Chae, Minhee, and Jinwoo Kim (2004), "Do Size and Structure Matter to Mobile Users? An Empirical Study of the Effects of Screen Size, Information Structure, and Task Complexity on User Activities with Standard Web Phones," Behaviour \& Information Technology, 23 (3), 165-181.

Cheema, Amar, and Andrew M. Kaikati (2010), "The Effect of Need for Uniqueness on Word of Mouth," Journal of Marketing Research, 3 (47), 553-563.

Chen, Zoey, and Nicholas H. Lurie (2013), "Temporal Contiguity and Negativity Bias in the Impact of Online Word of Mouth," Journal of Marketing Research, 50 (4), 463-476. 
Cheung, Cindy Man-Yee, Choon-Ling Sia, and Kevin KY Kuan (2012), “Is This Review Believable? A Study of Factors Affecting the Credibility of Online Consumer Reviews from an ELM Perspective,” Journal of the Association for Information Systems, 13 (8), 618-635.

Chevalier, Judith A., and Dina Mayzlin (2006) "The Effect of Word of Mouth on Sales: Online Book Reviews," Journal of Marketing Research, 43 (3), 345-354.

Chu, Shu-Chuan, and Sara Kamal (2008), “The Effect of Perceived Blogger Credibility and Argument Quality on Message Elaboration and Brand Attitudes: An Exploratory Study.” Journal of Interactive Advertising, 8 (2), 26-37.

Epley, Nicholas, Boaz Keysar, Leaf Van Boven, and Thomas Gilovich (2004), "Perspective Taking as Egocentric Anchoring and Adjustment,” Journal of Personality and Social Psychology, 87 (3), 327-39.

Feldman, Jack M., and John G. Lynch (1988), "Self-generated Validity and Other Effects of Measurement on Belief, Attitude, Intention, and Behavior,” Journal of Applied Psychology, 73 (3), 421-435.

Festinger, Leon (1957), A Theory of Cognitive Dissonance, Stanford: Stanford University Press.

Fong, Nathan M., Zheng Fang, and Xueming Luo (2015), "Geo-Conquesting: Competitive Locational Targeting of Mobile Promotions," Journal of Marketing Research, 52 (5), 726-735.

Forman, Chris, Anindya Ghose, and Batia Wiesenfeld (2008), “Examining the Relationship between Reviews and Sales: The Role of Reviewer Identity Disclosure in Electronic Markets,” Information Systems Research, 19 (3), 291-313.

Furner, Christopher P., and Robert A. Zinko (2017), “The Influence of Information Overload on the Development of Trust and Purchase Intention Based on Online Product Reviews in a Mobile vs. Web environment: An Empirical Investigation,” Electronic Markets, 27 (3), 211-224.

Ghose, Anindya, Avi Goldfarb, and Sang-Pil Han (2013), "How is the Mobile Internet Different? Search Costs and Local Activities,” Information Systems Research, 24 (3), 613-31.

Ghose, Anindya, and Panagiotis G. Ipeirotis (2011), "Estimating the Helpfulness and Economic Impact of Product Reviews: Mining Text and Reviewer Characteristics,” IEEE Transactions on Knowledge and Data Engineering, 23 (10), 1498-1512.

Godes, David, and Dina Mayzlin (2004), "Using Online Conversations to Study Word-of-mouth Communication," Marketing Science, 23 (4), 545-560. 
Grewal, Dhruv, Yakov Bart, Marin Spann, and Peter Pal Zubcsek (2016), "Mobile Advertising: A Framework and Research Agenda," Journal of Interactive Marketing, 34 (May), 3-14.

Grewal, Lauren, Andrew T. Stephen, and Nicole Verrochi Coleman (2019), "When Posting About Products on Social Media Backfires: The Negative Effects of Consumer Identity Signaling on Product Interest,” Journal of Marketing Research. Forthcoming.

Hayes, Andrew F. (2017), "Introduction to Mediation, Moderation, and Conditional Process Analysis: A Regression-based Approach,” New York, NY: Guilford Press.

Houser, Daniel, and John Wooders (2006), "Reputation in Auctions: Theory, and Evidence From eBay," Journal of Economics \& Management Strategy, 15 (2), 353-369.

Ito, Tiffany A., Jeff T. Larsen, N. Kyle Smith, and John T. Cacioppo (1998), "Negative Information Weighs More Heavily on the Brain: The Negativity Bias in Evaluative Categorizations." Journal of Personality and Social Psychology, 75 (4), 887-900.

John, Leslie K., Oliver Emrich, Sunil Gupta, and Michael I. Norton (2017), "Does "Liking” Lead to Loving? The Impact of Joining a Brand's Social Network on Marketing Outcomes," Journal of Marketing Research, 54 (1), 144-155.

Kruger, Justin, Derrick Wirtz, Leaf Van Boven, and T. William Altermatt (2004), “The Effort Heuristic,” Journal of Experimental Social Psychology, 40 (1), 91-98.

Lamberton, Cait and Andrew T. Stephen (2016), “A Thematic Exploration of Digital, Social Media, and Mobile Marketing Research’s Evolution from 2000 to 2015 and an Agenda for Future Research,” Journal of Marketing, 80 (6), 146-172.

Ludwig, Stephan, Ko De Ruyter, Mike Friedman, Elisabeth C. Brüggen, Martin Wetzels, and Gerard Pfann (2013), "More Than Words: The Influence of Affective Content and Linguistic Style Matches in Online Reviews on Conversion Rates," Journal of Marketing, 77 (1), 87-103.

Luo, Xueming, Michelle Andrews, Zheng Fang, and Chee Wei Phang (2013), "Mobile Targeting,” Management Science, 60 (7), 1738-1756.

März, Armin, Sebastian Schubach, and Jan H. Schumann (2017), ““Why Would I Read a Mobile Review?” Device Compatibility Perceptions and Effects on Perceived Helpfulness," Psychology \& Marketing, 34(2), 119-137.

Mayzlin, Dina, Yaniv Dover, and Judith Chevalier (2014), "Promotional Reviews: An Empirical Investigation of Online Review Manipulation," The American Economic Review, 104 (8), 2421-2455. 
McShane, Blakeley B., and Ulf Böckenholt (2017), "Single-Paper Meta-Analysis: Benefits for Study Summary, Theory Testing, and Replicability,” Journal of Consumer Research, 43 (6), 1048-1063.

Melumad, Shiri, Inman, Jeffery, J. and Michel Tuan Pham (2019), "Selectively Emotional: How Smartphone Use Changes User-Generated Content,” Journal of Marketing Research, Forthcoming.

Morales, Andrea C. (2005), “Giving Firms an 'E' for Effort: Consumer Responses to High-Effort Firms,” Journal of Consumer Research, 31(4), 806-12.

Moreau, C. Page, Leff Bonney, and Kelly B. Herd (2011), "It's the Thought (and the Effort) That Counts: How Customizing for Others Differs from Customizing for Oneself," Journal of Marketing, 75 (5), 120-33.

Mudambi, Susan M., and David Schuff (2010), "What Makes a Helpful Review? A Study of Customer Reviews on Amazon.com," MIS Quarterly, 34 (1), 185-200.

Norton, Michael I., Daniel Mochon, and Dan Ariely (2012), "The 'Ikea’ Effect: When Labor Leads to Love,” Journal of Consumer Psychology, 22 (July), 453-60.

Pan, Yue, and Jason Q. Zhang (2011), "Born Unequal: A Study of the Helpfulness of Usergenerated Product Reviews," Journal of Retailing, 87 (4), 598-612.

Petty, Richard E., John T. Cacioppo (1981), "Attitude and Persuasion: Classic and Contemporary Approaches,” Boulder, CO: Westview Press.

(1986), “The Elaboration Likelihood Model of Persuasion,” Advances in Experimental Social Psychology, 19, 123-205.

Ransbotham, Sam, N. Lurie, and Hongju Liu (2018), "Creation and Consumption of Mobile Word-of-Mouth: How are Mobile Reviews Different?,” Marketing Science.

Raptis, Dimitrios, Eleftherios Papachristos, Jesper Kjeldskov, Mikael B. Skov, and Nikolaos Avouris (2014), "Studying the Effect of Perceived Hedonic Mobile Device Quality on User Experience Evaluations of Mobile Applications," Behaviour \& Information Technology, 33 (11), 1168-1179.

Rosenthal, Robert and Ralph L. Rosnow (2008), Essentials of Behavioral Research: Methods and Data Analysis, 3rd ed. Boston: McGraw-Hill.

Schwarz, Norbert (2004), "Metacognitive Experiences in Consumer Judgment and Decision Making,” Journal of Consumer Psychology, 14 (4), 332-348.

Shah, Anuj K., and Daniel M. Oppenheimer (2008), "Heuristics Made Easy: An Effort-reduction Framework,” Psychological Bulletin, 134 (2), 207-222. 
Shankar, Venkatesh, Alladi Venkatesh, Charles Hofacker, and Prasad Naik (2010), "Mobile Marketing in the Retailing Environment: Current Insights and Future Research Avenues," Journal of Interactive Marketing, 24 (2), 111-120.

Sher, Peter J., and Sheng-Hsien Lee (2009), "Consumer Skepticism and Online Reviews: An Elaboration Likelihood Model Perspective," Social Behavior and Personality: An International Journal, 37 (1), 137-143.

Smith, Robert E., and Christine A. Vogt (1995) “The Effects of Integrating Advertising and Negative Word of Mouth Communications on Message Processing and Response,” Journal of Consumer Psychology, 4 (2), 133-152.

Statista (2018), “Mobile Internet - Statistics \& Facts,” https://tinyurl.com/ycdqdkkr.

Stephen, Andrew T. (2016), "The Role of Digital and Social Media Marketing in Consumer Behavior,” Current Opinion in Psychology, 10 (August), 17-21.

Stephen, Andrew T., and Jeff Galak (2012), “The Effects of Traditional and Social Earned Media on Sales: A Study of a Microlending Marketplace,” Journal of Marketing Research, 49 (5), 624-639.

Sundar, S. S. (2007), “Technology and Credibility: Cognitive Heuristics Cued by Modality, Agency, Interactivity and Navigability,” Digital media, youth, and credibility. MacArthur Foundation Series on Digital Media and Learning (pp. 73-100).

Sweeney, Simon, and Fabio Crestani (2006), "Effective Search Results Summary Size and Device Screen Size: Is there a Relationship?” Information Processing \& Management, 42 (4), 1056-1074.

Tirunillai, Seshadri, and Gerard J. Tellis (2012), "Does Chatter Really Matter? Dynamics of User-generated Content and Stock Performance," Marketing Science, 31 (2), 198-215.

Trusov, Michael, Randolph E. Bucklin, and Koen Pauwels (2009), "Effects of Word-of-mouth Versus Traditional Marketing: Findings from an Internet Social Networking Site," Journal of Marketing, 73 (5), 90-102.

Villanueva, Julian, Shijin Yoo, and Dominique M. Hanssens (2008), "The Impact of Marketinginduced versus Word-of-mouth Customer Acquisition on Customer Equity Growth," Journal of Marketing Research, 45 (1), 48-59.

Ward, Adrian F., Kristen Duke, Ayelet Gneezy, and Maarten W. Bos (2017), “Brain Drain: The Mere Presence of One’s Own Smartphone Reduces Available Cognitive Capacity,” Journal of the Association for Consumer Research, 2 (2), 140-154. 
Wilcox, Keith, and Andrew T. Stephen (2013), “Are Close Friends the Enemy? Online Social Networks, Self-esteem, and Self-control,” Journal of Consumer Research, 40 (1), 90-103.

Xiao, Bo and Izak Benbasat (2011), "Product-related Deception in E-commerce: A Theoretical Perspective,” MIS Quarterly, 35 (1), 169-196.

You, Ya, Gautham G. Vadakkepatt, and Amit M. Joshi (2015), "A Meta-analysis of Electronic Word-of-mouth Elasticity," Journal of Marketing, 2 (79), 19-39.

Zhang, Wei, and Stephanie A. Watts (2008), "Capitalizing on Content: Information Adoption in Two Online Communities.” Journal of the Association for Information Systems, 9 (2), 73-94.

Zhang, Yuchi, Michael Trusov, Andrew T. Stephen, and Zainab Jamal (2017), “Online Shopping and Social Media: Friends or Foes?” Journal of Marketing, 81 (6), 24 - 41.

Zhao, Yi, Yang, Sha, Narayan, Vishal and Ying Zhao (2013), "Modeling Consumer Learning from Online Product Reviews,” Marketing Science, 32(1), 153-169.

Zhu, Feng, and Xiaoquan Zhang (2010), "Impact of Online Consumer Reviews on Sales: The Moderating Role of Product and Consumer Characteristics," Journal of Marketing, 74 (2), 133-148. 
TABLE 1: SUMMARY OF MARKETING RESEARCH ON IMPACT OF MOBILE DEVICES

\begin{tabular}{|c|c|c|c|c|c|c|c|c|c|c|c|}
\hline \multirow[b]{2}{*}{ Authors } & \multicolumn{2}{|c|}{ Theoretical Focus } & \multicolumn{4}{|c|}{ Methodology } & \multirow[b]{2}{*}{ IV } & \multirow[b]{2}{*}{ Moderators } & \multirow[b]{2}{*}{ DV } & \multicolumn{2}{|c|}{ Key Mobile Finding } \\
\hline & $\begin{array}{l}\text { Advertising } \\
\text { /Apps }\end{array}$ & $\begin{array}{l}\text { Consumer } \\
\text { Attitudes } \\
\text { and } \\
\text { Behavior }\end{array}$ & $\begin{array}{l}\text { Information } \\
\text { Search/ } \\
\text { Internet } \\
\text { Behavior } \\
\end{array}$ & Conceptual & $\begin{array}{l}\text { Field } \\
\text { Data }\end{array}$ & Experimental & & & & $\begin{array}{l}\text { Positive/ } \\
\text { Increase }\end{array}$ & $\begin{array}{l}\text { Negative/ } \\
\text { Decrease }\end{array}$ \\
\hline $\begin{array}{l}\text { Shankar, } \\
\text { Venkatesh, } \\
\text { Hofacker, and } \\
\text { Naik (2010) }\end{array}$ & $\sqrt{ }$ & & & $\sqrt{ }$ & & & $\begin{array}{l}\text { Framework with the consumer, } \\
\text { the mobile, and the retailer }\end{array}$ & & & $\sqrt{ }$ & \\
\hline $\begin{array}{l}\text { Ghose, Goldfarb, } \\
\text { and Han (2013) }\end{array}$ & & & $\sqrt{ }$ & & $\sqrt{ }$ & & $\begin{array}{l}\text { Viewing Brand Posts on } \\
\text { Mobile or PC }\end{array}$ & & User click-behavior & & $\sqrt{ }$ \\
\hline $\begin{array}{l}\text { Lou, Andrews, } \\
\text { Fang, and Phang } \\
\text { (2013) }\end{array}$ & $\sqrt{ }$ & & & & & $\sqrt{ }$ (field) & $\begin{array}{l}\text { Received SMS message } \\
3 \text { distance x } 3 \text { time } \\
\text { manipulations }\end{array}$ & & $\begin{array}{l}\text { Purchase of } \\
\text { Promoted Movie }\end{array}$ & $\sqrt{ }$ & \\
\hline $\begin{array}{l}\text { Bart, Stephen, } \\
\text { and Sarvary } \\
\text { (2014) }\end{array}$ & $\sqrt{ }$ & & & & & $\sqrt{ }$ (field) & Exposure (or not) to mobile ad & $\begin{array}{l}\text { High (vs. Low) } \\
\text { Involvement and } \\
\text { Utilitarian (vs. } \\
\text { Hedonic) Products }\end{array}$ & $\begin{array}{l}\text { Attitudes and } \\
\text { Purchase Intentions }\end{array}$ & $\sqrt{ }$ & \\
\hline $\begin{array}{l}\text { Fong, Fang, and } \\
\text { Luo (2015) }\end{array}$ & $\sqrt{ }$ & & & & & $\sqrt{ }$ (field) & Mobile promotions & $\begin{array}{l}\text { Shopping area: } \\
\text { competitive, focal, } \\
\text { benchmark }\end{array}$ & Rate of returns & $\begin{array}{c}\sqrt{ } \\
\text { (competitive) }\end{array}$ & $\begin{array}{l}\sqrt{ } \\
\text { (local) }\end{array}$ \\
\hline $\begin{array}{l}\text { Grewal, Bart, } \\
\text { Spann, and } \\
\text { Zubcsek (2016) }\end{array}$ & $\sqrt{ }$ & & & $\sqrt{ }$ & & & $\begin{array}{l}\text { Framework with Context, } \\
\text { Consumer, Ad Goal, Ad } \\
\text { Elements }\end{array}$ & $\begin{array}{l}\text { Firm and Market } \\
\text { Factors }\end{array}$ & $\begin{array}{l}\text { Success of } \\
\text { Campaigns }\end{array}$ & $\sqrt{ }$ & \\
\hline $\begin{array}{l}\text { Furner and Zinko } \\
\text { (2017) }\end{array}$ & & $\sqrt{ }$ & $\sqrt{ }$ & & & $\sqrt{ }$ & $\begin{array}{l}\text { Reviews viewed on Mobile or } \\
\text { Non-mobile Device }\end{array}$ & Information Load & $\begin{array}{l}\text { Trust and Purchase } \\
\text { Intentions }\end{array}$ & $\sqrt{ }$ & $\sqrt{ }$ \\
\hline $\begin{array}{l}\text { März, Schubach, } \\
\text { and Schumann } \\
\text { (2017) }\end{array}$ & & $\sqrt{ }$ & & & $\sqrt{ }$ & $\sqrt{ }$ & $\begin{array}{l}\text { Actual Differences in Mobile } \\
\text { vs. Non-Mobile written online } \\
\text { review }\end{array}$ & $\begin{array}{l}\text { Compatibility with } \\
\text { Mobile }\end{array}$ & $\begin{array}{l}\text { Helpfulness and } \\
\text { Value }\end{array}$ & & $\sqrt{ }$ \\
\hline $\begin{array}{l}\text { Ward, Duke, } \\
\text { Gneezy, and Bos } \\
\text { (2017) }\end{array}$ & & $\sqrt{ }$ & & & & $\sqrt{ }$ & $\begin{array}{l}\text { Physical presence (or absence) } \\
\text { of smartphone }\end{array}$ & $\begin{array}{l}\text { Individual difference in } \\
\text { consumer smartphone } \\
\text { dependence }\end{array}$ & Cognitive Capacity & & $\sqrt{ }$ \\
\hline $\begin{array}{l}\text { Ransbotham, } \\
\text { Lurie, and Liu } \\
\text { (2018) }\end{array}$ & & $\sqrt{ }$ & & & $\sqrt{ }$ & & $\begin{array}{l}\text { Actual Differences in Mobile } \\
\text { vs. Non-Mobile written online } \\
\text { reviews }\end{array}$ & & Value & & $\sqrt{ }$ \\
\hline $\begin{array}{l}\text { Melumad, } \\
\text { Inman, and Pham } \\
\text { (2019) }\end{array}$ & & $\sqrt{ }$ & & & $\sqrt{ }$ & $\sqrt{ }$ & $\begin{array}{l}\text { Actual Differences in Mobile } \\
\text { vs. Non-Mobile UGC }\end{array}$ & & $\begin{array}{l}\text { Emotionality of } \\
\text { Content }\end{array}$ & N/A & N/A \\
\hline Current Study & & $\sqrt{ }$ & & & $\sqrt{ }$ & $\sqrt{ }$ & $\begin{array}{l}\text { Perceived Differences in } \\
\text { Mobile vs. Non-Mobile written } \\
\text { online reviews }\end{array}$ & $\begin{array}{l}\text { Cues that lower } \\
\text { perceived review } \\
\text { writing effort or } \\
\text { credibility, review } \\
\text { valence }\end{array}$ & $\begin{array}{l}\text { Helpfulness and } \\
\text { Purchase Intentions }\end{array}$ & $\sqrt{ }$ & \\
\hline
\end{tabular}


TABLE 2: OVERVIEW OF STUDIES

\begin{tabular}{|c|c|c|c|c|c|c|c|c|}
\hline \multirow{2}{*}{ Study } & \multirow{2}{*}{$\begin{array}{l}\text { Type of } \\
\text { Study }\end{array}$} & \multirow{2}{*}{ Data Source } & \multirow{2}{*}{ Sample Size* } & \multirow{2}{*}{ Moderator } & \multirow{2}{*}{ Measured Mediator } & \multirow{2}{*}{ DV } & \multicolumn{2}{|c|}{ Main Finding } \\
\hline & & & & & & & Mobile & Non-Mobile \\
\hline $\begin{array}{l}\text { Study } 1 \mathrm{~A} \\
\text { and } \\
\text { Study } 5\end{array}$ & Field Data & TripAdvisor & $\begin{array}{l}1,547,219 \\
\text { reviews }\end{array}$ & & & $\begin{array}{l}\text { Helpfulness } \\
\text { Count }\end{array}$ & $.94(1.49)$ & $.92(1.55)$ \\
\hline Study 1B & Experiment & MTurk & 369 (out of an & & & $\begin{array}{l}\text { Purchase } \\
\text { Intentions }\end{array}$ & $3.70(.75)$ & $\begin{array}{c}\text { Non-Mobile: } \\
3.35 \text { (.82) } \\
\text { Control: } 3.37(.87)\end{array}$ \\
\hline & & & initial 450) & & & Helpfulness & $4.25(.68)$ & $\begin{array}{c}\text { Non-Mobile: } \\
3.93 \text { (.94) } \\
\text { Control: } 4.02(.88)\end{array}$ \\
\hline Study 2A & Experiment & $\begin{array}{c}\text { Prolific } \\
\text { Academic }\end{array}$ & $\begin{array}{l}440 \text { (out of an } \\
\text { initial 480) }\end{array}$ & $\begin{array}{l}\text { Control } \\
\text { Effort Attribution }\end{array}$ & $\begin{array}{l}\text { Perceived Review } \\
\text { Writing Effort }\end{array}$ & $\begin{array}{l}\text { Purchase } \\
\text { Intentions }\end{array}$ & $\begin{array}{l}3.59(.88) \\
3.11(.76)\end{array}$ & $\begin{array}{c}3.28(1.03) \\
3.20(.86)\end{array}$ \\
\hline Study 2B & Experiment & Students & $\begin{array}{l}182 \text { (out of an } \\
\text { initial 212) }\end{array}$ & $\begin{array}{l}\text { Control } \\
\text { Effort Attribution }\end{array}$ & $\begin{array}{l}\text { Perceived Review } \\
\text { Credibility }\end{array}$ & $\begin{array}{l}\text { Purchase } \\
\text { Intentions }\end{array}$ & $\begin{array}{l}3.58(.88) \\
2.98(.73)\end{array}$ & $\begin{array}{l}3.18(.68) \\
3.21(.65)\end{array}$ \\
\hline Study 3 & Experiment & MTurk & $\begin{array}{l}394 \text { (out of an } \\
\text { initial 420) }\end{array}$ & $\begin{array}{c}\text { Control } \\
\text { External } \\
\text { Motivation }\end{array}$ & $\begin{array}{l}\text { Perceived Review } \\
\text { Writing Effort } \\
\text { Perceived Review } \\
\text { Credibility }\end{array}$ & $\begin{array}{l}\text { Purchase } \\
\text { Intentions }\end{array}$ & $\begin{array}{l}4.16(.59) \\
3.75(.84)\end{array}$ & $\begin{array}{l}3.88(.84) \\
3.67(.75)\end{array}$ \\
\hline Study 4 & Experiment & TurkPrime & $\begin{array}{l}414 \text { (out of an } \\
\text { initial 500) }\end{array}$ & $\begin{array}{l}\text { Positive } \\
\text { Negative }\end{array}$ & $\begin{array}{l}\text { Perceived Review } \\
\text { Writing Effort } \\
\text { Perceived Review } \\
\text { Credibility }\end{array}$ & $\begin{array}{l}\text { Purchase } \\
\text { Intentions }\end{array}$ & $\begin{array}{l}3.70(.99) \\
2.54(.91)\end{array}$ & $\begin{array}{l}2.65(.95) \\
2.36(.83)\end{array}$ \\
\hline WA & Experiment & MTurk & $\begin{array}{c}72 \text { (out of an } \\
\text { initial 80) }\end{array}$ & & & $\begin{array}{l}\text { Purchase } \\
\text { Intentions }\end{array}$ & $3.60(.83)$ & $3.25(.79)$ \\
\hline
\end{tabular}

*Across our experimental studies, we aimed for sample sizes between 100-150 participants per cell. Differences in sample sizes across studies stem from slight variation in the number of participants who were filtered out due to failing vital attention checks (i.e., remembering the device the review was written on or remembering review valence). Cleaning processes were consistent across all studies and decided in advance. Across studies, $5 \%-18 \%$ of participants failed attention checks. There were no statistical or demographic differences across conditions between participants who passed or failed these checks (see Web Appendix B for a table comparing included and excluded participants' characteristics). 
TABLE 3: NEGATIVE BINOMIAL REGRESSION RESULTS, STUDY 1A

\begin{tabular}{|c|c|c|c|}
\hline Variable & Baseline & $\begin{array}{c}\text { Controlling for } \\
\text { Review } \\
\text { Characteristics }\end{array}$ & $\begin{array}{l}\text { Controlling for } \\
\text { Review and } \\
\text { Reviewer } \\
\text { Characteristics }\end{array}$ \\
\hline $\begin{array}{l}\text { Mobile indicator } \\
(0=\text { absent, } 1 \text { = present })\end{array}$ & $\begin{array}{r}.024 \\
(25.07)^{*}\end{array}$ & $\begin{array}{r}.027 \\
(33.36)^{*}\end{array}$ & $\begin{array}{c}.024 \\
(24.15)^{*}\end{array}$ \\
\hline $\begin{array}{l}\text { Review length } \\
\text { (characters) }\end{array}$ & & $\begin{array}{r}.0005 \\
(9,882.15)^{*}\end{array}$ & $\begin{array}{r}.0003 \\
(4,508.97)^{*}\end{array}$ \\
\hline $\begin{array}{l}\text { Hotel response } \\
(0=\text { no, } 1=\text { yes })\end{array}$ & & $\begin{array}{r}-.207 \\
(7,564.30)^{*}\end{array}$ & $\begin{array}{r}-.101 \\
(2,274.62)^{*}\end{array}$ \\
\hline $\begin{array}{l}\text { Rating } \\
(1-5)\end{array}$ & & $\begin{array}{r}-.184 \\
(34,374.70)^{*}\end{array}$ & $\begin{array}{r}-.090 \\
(9,846.27)^{*}\end{array}$ \\
\hline $\begin{array}{l}\text { Mean reviewer } \\
\text { helpfulness }\end{array}$ & & & $\begin{array}{r}.604 \\
(354,655.00)^{*}\end{array}$ \\
\hline $\begin{array}{l}\text { Top contributor } \\
(0=\text { no, } 1=\text { yes })\end{array}$ & & & $\begin{array}{r}.078 \\
(848.30)^{*}\end{array}$ \\
\hline Intercept & $\begin{array}{r}-.084 \\
(4,464.79)^{*} \\
\end{array}$ & $\begin{array}{r}.521 \\
(11,131.10)^{*}\end{array}$ & $\begin{array}{r}-.651 \\
(18,548.30)^{*}\end{array}$ \\
\hline Dispersion parameter & 1.173 & 1.053 & .387 \\
\hline AIC & 4,112,476.89 & $4,060,517.83$ & $3,479,264.72$ \\
\hline BIC & $4,112,513.65$ & $4,060,591.34$ & $3,479,362.73$ \\
\hline $\mathrm{N}$ & $1,547,219$ & $1,547,219$ & $1,547,219$ \\
\hline
\end{tabular}


TABLE 4: MEDIATION TABLES ACROSS STUDIES 2A AND 2B

Study 2A: Moderated Mediation

\begin{tabular}{|c|c|c|c|c|c|c|c|c|}
\hline \multirow[b]{2}{*}{ Antecedent } & \multicolumn{4}{|c|}{ M (Effort) } & \multicolumn{4}{|c|}{ Y (Purchase Intentions) } \\
\hline & Coeff. & SE & $t$ & $p$ & Coeff. & SE & $t$ & $p$ \\
\hline X (Device) & .0349 & .0491 & .7116 & .4771 & .0335 & .0397 & .8437 & .3993 \\
\hline M (Effort) & --- & --- & --- & --- & .3287 & .0498 & 6.5987 & $<.0001$ \\
\hline W (Attribution) & -.1456 & .0491 & -2.9662 & .0032 & -.1019 & .0401 & -2.5437 & .0113 \\
\hline Device*Attribution & -.1563 & .0491 & -3.1830 & .0016 & -.0475 & .0407 & -1.1681 & .2434 \\
\hline Constant & 4.5798 & .0491 & 93.2875 & $<.0001$ & 3.846 & .1280 & 30.053 & $<.0001$ \\
\hline \multicolumn{2}{|c|}{ Model Summary } & \multicolumn{4}{|c|}{$\mathrm{R}^{2}=.0435$} & \multicolumn{3}{|c|}{$\mathrm{R}^{2}=.1889$} \\
\hline & & \multicolumn{4}{|c|}{$\mathrm{F}(3,436)=93.2875, p<.0001$} & \multicolumn{3}{|c|}{$\mathrm{F}(4,435)=9.9891, p<.000$} \\
\hline
\end{tabular}

Study 2B: Moderated Mediation

\begin{tabular}{|c|c|c|c|c|c|c|c|c|}
\hline \multirow[b]{2}{*}{ Antecedent } & \multicolumn{4}{|c|}{ M (Credibility) } & \multicolumn{4}{|c|}{ Y (Purchase Intentions) } \\
\hline & Coeff. & SE & $t$ & $p$ & Coeff. & SE & $t$ & $p$ \\
\hline X (Device) & .1273 & .0620 & 2.052 & .0417 & .1273 & .0619 & 1.3569 & .1766 \\
\hline M (Credibility) & --- & --- & --- & --- & .5141 & .0739 & 6.9574 & $<.0001$ \\
\hline W (Attribution) & .0041 & .0620 & .0654 & .9479 & .0188 & .0612 & .3069 & .7593 \\
\hline Device*Attribution & -.1707 & .0620 & -2.7517 & .0065 & .0760 & .0625 & 1.2169 & .2253 \\
\hline Constant & 4.1697 & .0620 & 67.2051 & $<.0001$ & 1.2293 & .3141 & 3.9130 & .0001 \\
\hline \multicolumn{2}{|c|}{ Model Summary } & \multicolumn{4}{|c|}{$\mathrm{R}^{2}=.0660$} & \multicolumn{3}{|c|}{$\mathrm{R}^{2}=.2155$} \\
\hline & & \multicolumn{4}{|c|}{$\mathrm{F}(3,178)=4.1924, p=.0068$} & \multicolumn{3}{|c|}{$\mathrm{F}(4,177)=12.1541, p<.0001$} \\
\hline
\end{tabular}


FIGURE 1: CONCEPTUAL FRAMEWORK

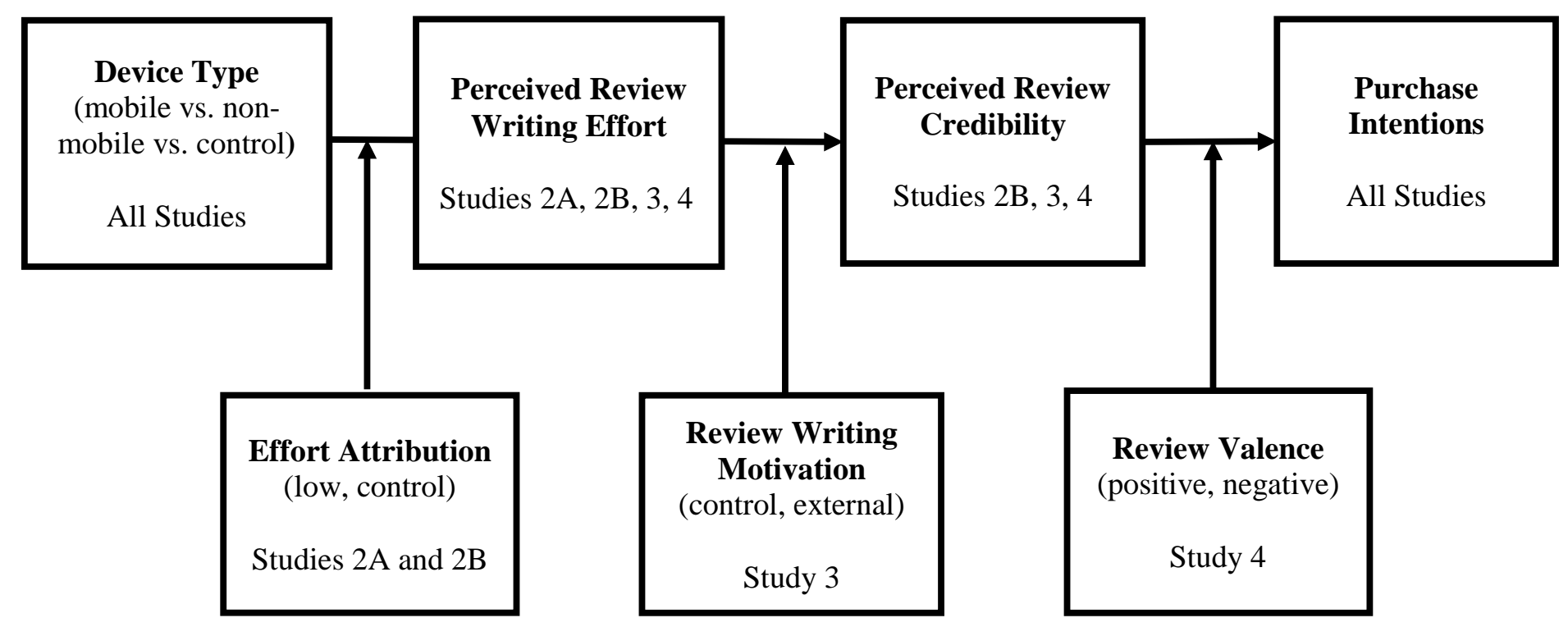


FIGURE 2: REVIEW STIMULI ACROSS STUDIES

\section{Mobile Hotel Review \\ (Studies 1B, 2A, 2B, 4)}

\section{Non-mobile (Desktop) Hotel Review (Studies 1B, 2A, 2B, 4)}

"Good location, dated rooms"

"Good location, dated rooms"

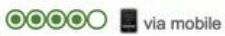

Excellent location to enjoy New Orleans. Attached to good shopping and easy to walk to French Quarter. Close to convention centre. Still needs some room upgrade! Sink area is small and restrictive. No counter space and hard to get close to mirror.

Drago's a great restaurant,separately reviewed,lobby bar pleasant with good TV sight lines.

If you are looking for a bit of luxury and something special, you can do better. Even close to convention centre.

Clean, comfortable average hotel with good location. Nothing special.

Less $\triangle$

Was this review helpful? Yes

\section{Mobile Hotel Review (Study 3)}

"A weekend in Boston" ○000 Dvia mobile

This is a very good hotel in a rapidly developing part of Boston. It is not in one of the main tourist areas but is very well situated next to the World Trade Centre and the Silver Line subway train station is just behind the hotel, making it very easy to get around Boston economically or to get to Logan airpost. The hotel restaurant is good but there are many other good restaurants close by and the area was very lively on Friday and Saturday night. We particularly appreciated the non-tipping policy of the hotel (though this is paid for by an automatic $18 \%$ addition to all bills. However, for visitors to the USA this makes for a more relaxing experience.

\section{"A weekend in Boston"}

\section{O0000 Qvia mobile}

This is a very good hotel in a rapidly developing part of Boston. It is not in one of the main tourist areas but is very well situated next to the World Trade Centre and the Silver Line subway train station is just behind the hotel, making it very easy to get around Boston economically or to get to Logan airpost. The hotel restaurant is good but there are many other good restaurants close by and the area was very lively on Friday and Saturday night. We particularly appreciated the non-tipping policy of the hotel (though this is paid for by an automatic $18 \%$ addition to all bills. However, for visitors to the USA this makes for a more relaxing experience.
00000 므 via desktop

Excellent location to enjoy New Orleans. Attached to good shopping and easy to walk to French Quarter. Close to convention centre. Still needs some room upgrade! Sink area is small and restrictive. No counter space and hard to get close to mirror.

Drago's a great restaurant,separately reviewed,lobby bar pleasant with good TV sight lines.

If you are looking for a bit of luxury and something special, you can do better. Even close to convention centre.

Clean,comfortable average hotel with good location. Nothing special.

Less 4

Was this review helpful? Yes

\section{Non-mobile (Desktop) Hotel Review (Study 3)}

"A weekend in Boston"

○○○○ 므 via desktop

This is a very good hotel in a rapidly developing part of Boston. It is not in one of the main tourist areas but is very well situated next to the World Trade Centre and the Silver Line subway train station is just behind the hotel, making it very easy to get around Boston economically or to get to Logan airpost. The hotel restaurant is good but there are many other good restaurants close by and the area was very lively on Friday and Saturday night. We particularly appreciated the non-tipping policy of the hotel (though this is paid for by an automatic $18 \%$ addition to all bills. However, for visitors to the USA this makes for a more relaxing experience.

"A weekend in Boston" ○००○ 므 via desktop

This is a very good hotel in a rapidly developing part of Boston. It is not in one of the main tourist areas but is very well situated next to the World Trade Centre and the Silver Line subway train station is just behind the hotel, making it very easy to get around Boston economically or to get to Logan airpost. The hotel restaurant is good but there are many other good restaurants close by and the area was very lively on Friday and Saturday night. We particularly appreciated the non-tipping policy of the hotel (though this is paid for by an automatic $18 \%$ addition to all bills. However, for visitors to the USA this makes for a more relaxing experience, 


\section{FIGURE 3: MEDIATION FIGURES FOR STUDIES 3 AND 4}

\section{STUDY 3: SERIAL MODERATED MEDIATION}

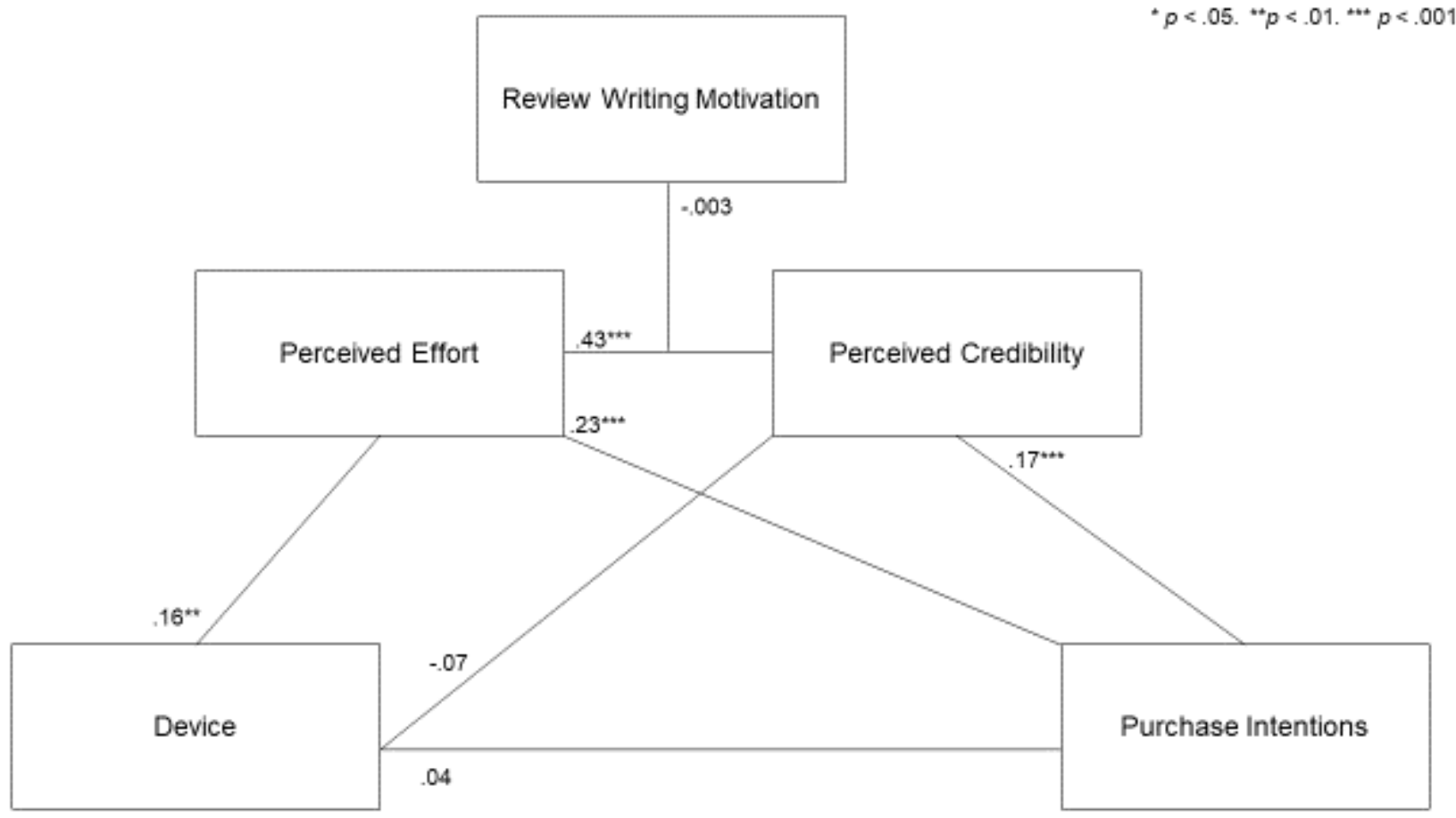

STUDY 4: SERIAL MEDIATED MODERATION

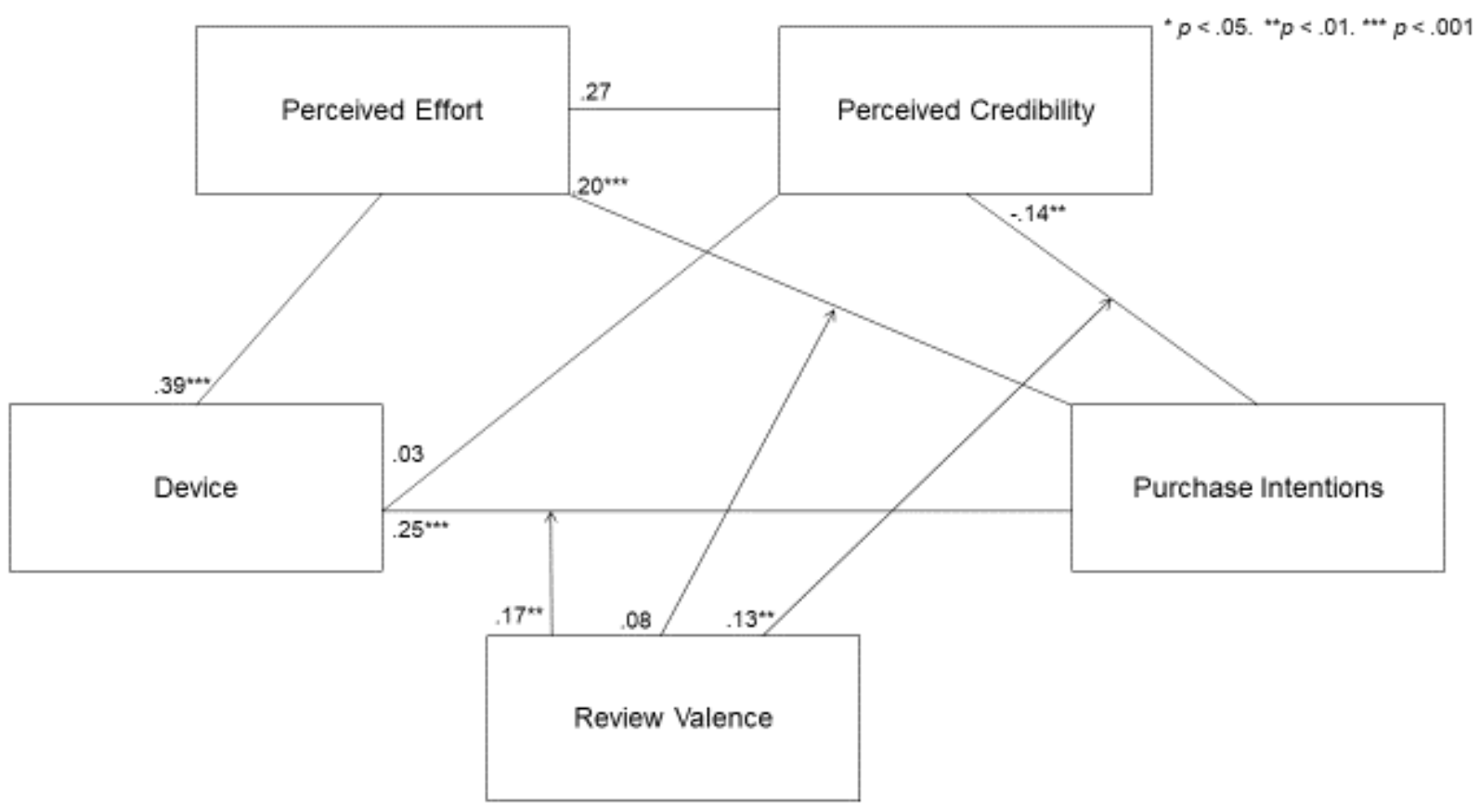


WEB APPENDIX FOR IN MOBILE WE TRUST: THE EFFECTS OF MOBILE VERSUS NON-MOBILE REVIEWS ON CONSUMER PURCHASE INTENTIONS

\author{
Lauren Grewal
}

Andrew T. Stephen

\title{
Web Appendix
}

This document contains stimuli, manipulations, manipulation checks, dependent measures, pretests, and supplemental material referred to in the original manuscript. 


\section{Web Appendix A: TripAdvisor Data}

(ii) Name of hotel would be listed based on search

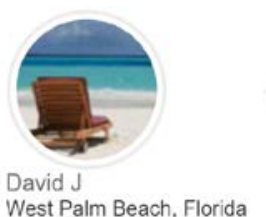

(v) Level 4 contributor

(vi) 25 reviews

周 7 hotel reviews

(B) 5 helpful votes
"In town for a conference and stayed at the Seaport NEW Hotel"

(i) $\bigcirc 000$ Reviewed yesterday (日) via mobile (viii)

My wife and I stayed here for a conference and we opted for the suite. The room was new, very nicely appointed and clean. One of my favorite things about the room was the fact that we had separate $A / C$ in our living room and in our bedroom. Since I keep the bedroom colder than the living area it was nice to not have to wait for the room to warm up to be comfortable in the morning. Our room service arrived right on time every time and was very good.

Stayed July 2016, traveled on business

Less -

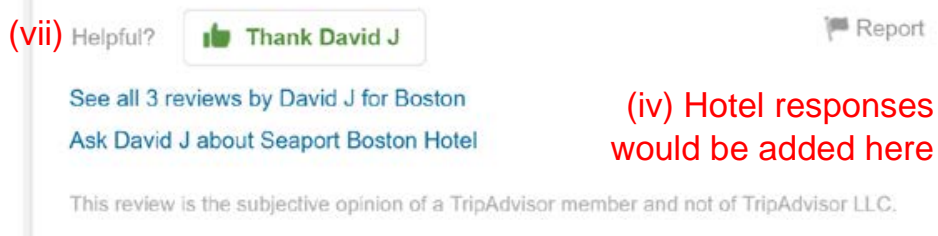

(i) The rating given by the reviewer (1 to 5; with 5 the most positive)

(ii) Hotel name and location

(iii) Review date, headline, and full text

(iv) Whether the hotel responded to the review

(v) Whether the reviewer was recognized as a "Top Contributor" by TripAdvisor

(vi) The number of reviews the reviewer had written at the time data collection

(vii) The number of helpful votes the reviewer had received across all their reviews at the time of data collection

(viii) Whether there was an indication of "via mobile" on the review or not 
Web Appendix B: Distribution of Participants Included and Excluded from Experimental Studies

\begin{tabular}{|c|c|c|}
\hline Study Number & Excluded Demographics/Condition & Included Demographics/Condition \\
\hline Study 1B & $\begin{array}{c}\text { Control: } \mathrm{n}=25 \\
\text { Mobile: } \mathrm{n}=27 \\
\text { Non-Mobile: } \mathrm{n}=30 \\
\mathrm{M}_{\text {age }}=37.90,52 \% \text { female }\end{array}$ & $\begin{array}{c}\text { Control: } \mathrm{n}=124 \\
\text { Mobile: } \mathrm{n}=123 \\
\text { Non-Mobile: } \mathrm{n}=122 \\
\mathrm{M}_{\text {age }}=36.07,48 \% \text { female }\end{array}$ \\
\hline Study 2A & $\begin{array}{c}\text { Mobile: } \mathrm{n}=23 \\
\text { Non-Mobile: } \mathrm{n}=17 \\
\mathrm{M}_{\text {age }}=33.45,38 \% \text { female }\end{array}$ & $\begin{array}{c}\text { Mobile: } \mathrm{n}=222 \\
\text { Non-Mobile: } \mathrm{n}=218 \\
\mathrm{M}_{\text {age }}=31.18,42 \% \text { female }\end{array}$ \\
\hline Study 2B & $\begin{array}{c}\text { Mobile: } \mathrm{n}=18 \\
\text { Non-Mobile: } \mathrm{n}=22 \\
\mathrm{M}_{\text {age }}=20.44,48 \% \text { female }\end{array}$ & $\begin{array}{c}\text { Mobile: } \mathrm{n}=92 \\
\text { Non-Mobile: } \mathrm{n}=90 \\
\mathrm{M}_{\text {age }}=20.49,50 \% \text { female }\end{array}$ \\
\hline Study 3 & $\begin{array}{c}\text { Mobile: } 16 \\
\text { Non-Mobile: } 10 \\
\mathrm{M}_{\text {age }}=34.90,46 \% \text { female }\end{array}$ & $\begin{array}{c}\text { Mobile: } 194 \\
\text { Non-Mobile: } 200 \\
\mathrm{M}_{\text {age }}=35.05,43 \% \text { female }\end{array}$ \\
\hline Study 4 & $\begin{array}{c}\text { Mobile: } \mathrm{n}=46 \\
\text { Non-Mobile: } \mathrm{n}=40 \\
\mathrm{M}_{\text {age }}=45.59,50 \% \text { female }\end{array}$ & $\begin{array}{c}\text { Mobile: } \mathrm{n}=200 \\
\text { Non-Mobile: } \mathrm{n}=214 \\
\mathrm{M}_{\mathrm{age}}=43.89,56 \% \text { female }\end{array}$ \\
\hline
\end{tabular}


Web Appendix C: Items used for Manipulation Checks across Studies as Criteria for Dropping Participants

\section{Device Manipulation Check:}

From what type of device did the reviewer post the review you read in today's task?
Desktop
Mobile
I cannot remember

\section{Review Rating Manipulation Check:}

What rating (from 1 to 5 ) did the reviewer give this hotel?

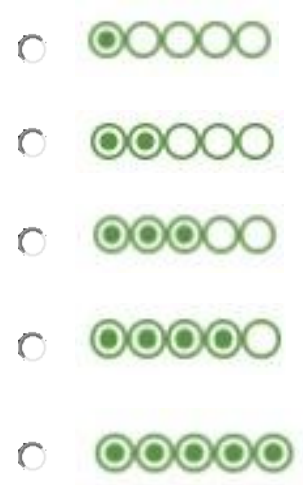




\section{Web Appendix D: Instructions Used in Review Tasks}

“On the next screen you will be asked to examine a hotel review from the popular travel website Tripadvisor.com. The review is for a restaurant in hotel in New Orleans. The review is a user-generated review (i.e., written by a regular person).

The review is on the next screen and appears as a screenshot taken directly from TripAdvisor. When you look at this screenshot please take your time (about 1 minute).

In particular, please pay attention to all aspects of the review shown in the screenshot: the review's title, the rating given (1 to 5), how the review was posted (mobile or desktop), and, of course, the text of the review itself.

It is important that you focus on each of these aspects, because after viewing this screenshot of a TripAdvisor restaurant review we will ask you questions about some of these things.” 


\section{Web Appendix E: Replication of Results in Different Service Context}

We use an experimental design to examine whether the impact of knowing a UGC review was written on a mobile device increases purchase consideration for a reviewed restaurant. Importantly, this study conceptually replicates the findings throughout the paper that knowing a review was from a mobile device leads to an increase in consumers' favorable attitudes toward a review. In this case, we capture this main effect through seeing changes in purchase intention for the reviewed restaurant (vs. hotel reviews).

\section{Method}

Eighty Amazon Mechanical Turk members who reported owning a mobile device such as a smartphone participated in this survey for nominal payment $\left(\mathrm{M}_{\mathrm{age}}=35.05,45 \%\right.$ female $)$. The restaurant used in the stimuli was in Boston, so we also restricted participant recruitment to people who had not been to Boston to reduce the likelihood of participants having prior knowledge of or familiarity with the restaurant. Participants were randomly assigned to one of two conditions (mobile, non-mobile) in a between-subjects design. Eight participants were dropped because they did not pass a manipulation check towards the end of the study that asked them to recall if the review they read was either "via mobile” or "via desktop.” This left us with data from 72 participants.

Participants were informed that they would engage in a task that was concerned with how mobile devices are used for online behavior. To make this task appear as realistic as possible and in support of this cover story, we first asked participants a number of general questions about owning a mobile device (i.e., if they owned a device and if so, what type of mobile device; participants who did not own a mobile device were screened out of the study), their daily 
behavior for engaging with social and digital media through their devices (i.e., percentage of time spent online daily is via a mobile device versus a non-mobile device like a desktop), and whether or not their mobile devices are ever used for reading or writing online reviews.

Participants then completed a "Restaurant Review Task.” We told participants that they would see a user-generated review taken from TripAdvisor.com for a restaurant located in the Boston area, be asked to read this review, and answer some questions about it. In both conditions the same review, which was moderately positive, was shown. No reviewer information was provided, and the only difference between the review stimuli across conditions was the label indicating from which type of device the review was posted. In the mobile condition the label said “via mobile," identical to what actually appears on TripAdvisor. In the non-mobile condition, the label said "via desktop", which we use to reduce ambiguity in the non-mobile condition (which could otherwise confound this manipulation if there was no such label in the non-mobile condition, since in the mobile condition the generation source is not ambiguous).

After reading the review, participants were asked to imagine that they were planning a visit to Boston and needed to find a breakfast restaurant. We then asked them to indicate how likely they would be to eat at this restaurant ( $1=$ not at all Consider, $5=$ definitely would consider). Finally, we asked our manipulation check and standard demographic questions. Results and Discussion

To test our prediction that purchase consideration should be higher in the mobile condition we regressed purchase consideration on a dummy variable for experimental condition (mobile $=1$, non-mobile $=0$ ). Results are in line with our prediction. There was a significant positive effect of mobile $(\mathrm{b}=.44, \mathrm{t}=2.10, p=.04)$ such that participants who saw the "via mobile" label were more likely to consider eating at the restaurant $(\mathrm{M}=3.60, \mathrm{SD}=.83)$ than 
those who saw the "via desktop" label $(\mathrm{M}=3.25, \mathrm{SD}=.79)$. This finding is conceptually consistent with the main findings from the TripAdvisor data in Study 1A, and the experimental replication in Study 1B. 


\section{Web Appendix F: Effort Pre-test}

Prior to running process studies regarding the perceived review writing effort, we ran a pre-test on the type of effort that is activated when people consider mobile-written reviews.

Undergraduates in the lab ( $\mathrm{n}=198, M_{\text {age }}=20,40 \%$ female) were told to imagine an online review that was either written via mobile or via desktop. They were asked how effortful they believed the review writing process would have been for this review across six items that represented three different types of effort: physical effort $(\alpha=.84)$, cognitive effort $(\alpha=.81)$, and emotional effort $(\alpha=.84)$. The study revealed that participants found mobile-written reviews to be more physically effortful to create $(b=.35, t=2.02, p=.045)$. There were no significant differences in perceived cognitive effort $(\mathrm{b}=-.07, \mathrm{t}=-.475, p=.635)$, nor were there significant differences in perceived emotional effort $(\mathrm{b}=.19, \mathrm{t}=1.01, p=.316)$.

- The consumer put a lot of physical effort into writing this post (Physical Effort)

- The consumer put a lot of mental effort into writing this post (Mental Effort)

- The consumer put a lot of emotional effort into writing this post (Emotional Effort)

- Compared to the average consumer who posts on $\mathrm{X}$, this consumer put more physical effort into writing this post (Physical Effort)

- Compared to the average consumer who posts on $\mathrm{X}$, this consumer put more mental effort into writing this post (Mental Effort)

- Compared to the average consumer who posts on $\mathrm{X}$, this consumer put more emotional effort into writing this post (Emotional Effort) 


\section{Web Appendix G: Effort Attribution Manipulation (Studies 2A, 2B)}

Online review sites have increased the ease for readers and writers of their reviews. While it used to be more difficult for people to read and write reviews from mobile devices compared to desk top computers, with new apps for different types of mobile devices, the ease of writing and posting these reviews has gone up.

In a separate study we conducted, when people who write online reviews from both non-mobile and mobile devices were asked about the amount of effort it takes them to write their reviews, the average value given for both types of reviews was a 5 out of 7 on effort. These reviewers who write for TripAdvisor found that there was absolutely no difference in their levels of effort when writing an online review, regardless of what they wrote the review on.

Please click $>>$ to see the review (which appears as a screenshot from Tripadvisor.com). 
Web Appendix H: Items used to Measure Review Writing Effort (Studies 2A, 3, 4)

- The reviewer put a lot of effort into writing this review.

- The reviewer took time to craft this review.

- The reviewer put a lot of thought into this review.

- The reviewer went to some trouble to write this review.

- The reviewer had to go out of his/her way to write this review.

- Compared to the average reviewer, this reviewer put more effort into writing this review. 


\section{Web Appendix I: Alternative Explanations Items (Studies 2A and 4)}

- This review was unbiased.

- This review was trustworthy.

- This review was clear.

- This review was easy to understand.

- This review was persuasive.

- This review was convincing.

- This review was comprehensive.

- This review was highly informative.

- This review was spontaneously written.

- This review was written without a lot of thought.

- This person knows what they are talking about.

- This person knows how to evaluate hotels.

- This person is an expert on hotels.

- This person had an ulterior motive.

- This person was biased.

- This person was unreasonable.

- This person is like me.

- This person has tastes similar to mine (for hotels).

- I believe this reviewer is like me.

- This person gave thoughts that were not well formed.

- This person gave an opinion that seemed incomplete.

- This person stated views in a rushed or hurried manner.

- This reviewer does not believe what they wrote in their review.

- This review was likely written around the time of the reviewer's stay at this hotel.

- The reviewer likely wrote this review while his/her experience was still fresh in his/her mind.

- The information in this review was an accurate depiction of the reviewer's subjective stay and opinions.

- The information in this review was diagnostic of the reviewer's stay and opinions.

- The reviewer was honest in their review.

- The reviewer can be trusted.

- The review was written because the reviewer was being compensated in some way for the review.

- The review was written to help other people make an informed decision about staying at the hotel.

- The reviewer was motivated to write a review that would let people make their own conclusions about the hotel.

- The reviewer was motivated to sell people on the hotel through their review. 


\section{Web Appendix J: Credibility Items (Study 2B)}

\section{Credibility Items:}

- The information in this review was an accurate depiction of the reviewer's subjective stay and opinions.

- The information in this review was diagnostic of the reviewer's stay and opinions.

- The reviewer was honest in their review.

- The reviewer can be trusted.

- The review was written to help other people make an informed decision about staying at the hotel.

- The reviewer was motivated to write a review that would let people make their own conclusions about the hotel. 


\section{Web Appendix K: Open Response Coding Findings (Study 3)}

\section{Coding Open Response Instructions}

Answer the following questions below for how you think the writer of the response interpreted the online review they discussed.

This person who read the review...

- believed the review was authentic

- believed that the review was genuine

- believed that the reviewer wanted to help others

- believed that reviewer wanted to share their experience

- believed that the reviewer was paid to write the review

- believed that the review was written because the reviewer was given something from the hotel for doing so

- was uncertain as to why the reviewer wrote the review

- believed that the reviewer was a trustworthy source of information

- believed that the reviewer gave an accurate description of their stay

- believed that the review was worthwhile to read

- believed that the review contained useful information

- believed that the reviewer wrote the review because they enjoy writing reviews

- believed that the reviewer wanted to share their knowledge

- believed that the reviewer was motivated to accurately describe their stay

- believed the review was written as the reviewer had something they wanted to say

In Study 3 we wanted to address the possible motivations behind why consumers believe someone has posted a review from a mobile device. To do this, we had participants write in an open response after reading the review, why they believed the reviewer wrote their review. They were asked what the reviewer's motivation might have been, what their goals may have been, and what were they trying to accomplish.

Coding Results of Reviewer Motivations. Considering the responses from coders regarding why they believed reviews were written, we regressed the average of each item (across the three coders) on device type (non-mobile $=-1$, mobile $=1$ ), motivation (control $=-1$, external $=1$ ), and their interaction. We had no specific predictions about how these results would appear. 
We found no significant main effect of device type on any of our items (all $p>$.08). The “perceived accuracy of the description” was marginally significant $(p=.081)$, where coders believed that mobile reviews were more accurate $(\mathrm{M}=5.12, \mathrm{SD}=1.46)$ than non-mobile reviews $(M=5.00, S D=1.49)$. We found a main effect of motivation on every item except for uncertainty about review writer motivation $\left(p_{\text {uncertain }}=.266\right.$, all other $\left.p<.003\right)$. Reviews that were externally motivated (vs. the control condition) were considered less authentic, genuine, trustworthy, accurate, worthwhile, and informative. As well, they were seen as not being written to help others, wanting to share experience, done because of review writing enjoyment, wanting to share knowledge, motivated to accurately describe experience, or having something to say. We found two significant interactions; (1) how trustworthy the information was (b = $.122, \mathrm{t}=1.66, p=.098)$, and (2) how accurate the description was believed to be $(\mathrm{b}=.15, \mathrm{t}=$ $1.98, p=.049)$. In both cases, in the control condition, mobile reviews were believed as being more trustworthy and accurate than the non-mobile review $\left(p_{\text {trust }}=.131\right.$; $\left.p_{\text {accuracy }}=.078\right)$. The simple effect of device was not significant when the review was externally motivated $\left(p_{\text {trust }}=\right.$ $.349 ; p_{\text {accuracy }}=.245$ ). We additionally found no moderated mediation (all CI95 included 0). 


\section{Web Appendix L: Robustness Checks to Mediation Models in Studies 3 and 4}

Study 3: As a robustness check, we again tested the complete mechanism (i.e., mobile $\rightarrow$ effort $\rightarrow$ credibility $\rightarrow$ purchase intentions) by estimating two serial mediation models (Hayes 2017, PROCESS Model 6): one under the control condition, and another under the external motivation condition. In the control condition, we again found that the indirect effect of mobile on purchase intentions through this serial pathway was positive and significant $(\mathrm{b}=.08, \mathrm{SE}=.03$, CI95 $[.03, .15])$; other indirect pathways with these mediating variables were not significant when switched. In the external motivation condition, as expected, the conceptualized pathway was not significant $\left(\mathrm{b}=.002, \mathrm{SE}=.003, \mathrm{CI}_{95}[-.045, .001]\right)$.

Study 4: As a robustness check, we again tested the complete mechanism (i.e., mobile $\rightarrow$ effort $\rightarrow$ credibility $\rightarrow$ purchase intentions) by estimating two serial mediation models (Hayes 2017, PROCESS Model 6): one in the positive review condition and one in the negative review condition. In the positive review condition, we found that the indirect effect of mobile on purchase intentions through this serial pathway was positive and significant $(b=.03, \mathrm{SE}=.01$, CI95 $[.01, .06])$; other indirect pathways with these mediating variables were not significant when switched. In the negative review condition, as predicted, the conceptualized pathway was not significant $\left(\mathrm{b}=-.001, \mathrm{SE}=.007, \mathrm{CI}_{95}[-.02, .01]\right)$. 


\section{Web Appendix M: Tables for Mediation Models in Studies 3 and 4}

\section{Study 3: Serial Moderated Mediation (Model 91)}

Consequent

\begin{tabular}{|c|c|c|c|c|c|c|c|c|c|c|c|c|}
\hline \multirow[b]{2}{*}{ Antecedent } & \multirow[b]{2}{*}{ Coeff. } & \multicolumn{4}{|c|}{$M_{1}$ (Effort) } & \multicolumn{3}{|c|}{$\mathrm{M}_{2}$ (Credibility) } & \multicolumn{4}{|c|}{ Y (Purchase Intentions) } \\
\hline & & SE & $T$ & $P$ & Coeff. & SE & $T$ & $p$ & Coeff. & $\mathrm{SE}$ & $t$ & $p$ \\
\hline X (Device) & .1617 & .0497 & 3.2557 & .0012 & -.0734 & .0433 & -1.6963 & .0906 & .0514 & .0359 & 1.4324 & .1528 \\
\hline $\mathrm{M}_{1}$ (Effort) & --- & --- & --- & --- & .4333 & .0617 & 7.0197 & $<.0001$ & .2358 & .0400 & 5.8890 & $<.0001$ \\
\hline $\mathrm{M}_{2}$ (Credibility) & --- & --- & --- & --- & --- & --- & --- & --- & .1777 & .0418 & 4.2510 & $<.0001$ \\
\hline W (Motivation) & --- & -- & -- & --- & -.0033 & .4428 & -.0074 & .9941 & --- & --- & --- & --- \\
\hline Effort $*$ Motivation & --- & --- & --- & --- & .0275 & .0864 & .3186 & .7502 & --- & --- & --- & --- \\
\hline \multirow[t]{2}{*}{ Constant } & 5.032 & .0497 & 101.28 & $<.0001$ & 3.3190 & .3246 & 10.223 & $<.0001$ & 1.7183 & .2290 & 7.5051 & $<.0001$ \\
\hline & & \multicolumn{4}{|c|}{$\mathrm{R}^{2}=.0263$} & \multicolumn{3}{|c|}{$\mathrm{R}^{2}=.2057$} & \multicolumn{4}{|c|}{$\mathrm{R}^{2}=.2043$} \\
\hline & & \multicolumn{4}{|c|}{$\mathrm{F}(1,392)=10.59994, p=.0012$} & \multicolumn{3}{|c|}{$\mathrm{F}(4,389)=25.2564, p<.0001$} & \multicolumn{4}{|c|}{$\mathrm{F}(3,390)=33.4570, p<.0001$} \\
\hline
\end{tabular}

Study 4: Serial Mediated Moderation (Model 89)

\begin{tabular}{|c|c|c|c|c|c|c|c|c|c|c|c|c|}
\hline \multicolumn{13}{|c|}{ Consequent } \\
\hline \multirow[b]{2}{*}{ Antecedent } & \multirow[b]{2}{*}{ Coeff. } & \multicolumn{4}{|c|}{$\mathrm{M}_{1}$ (Effort) } & \multicolumn{3}{|c|}{$\mathbf{M}_{2}$ (Credibility) } & \multicolumn{4}{|c|}{ Y (Purchase Intentions) } \\
\hline & & SE & $T$ & $P$ & Coeff. & SE & $T$ & $p$ & Coeff. & SE & $t$ & $p$ \\
\hline X (Device) & .3906 & .0502 & 7.5173 & $<.0001$ & 0339 & .0469 & .7222 & .4706 & .2536 & .0467 & 5.428 & $<.0001$ \\
\hline $\mathrm{M}_{1}$ (Effort) & --- & --- & --- & --- & .2729 & .0417 & 6.545 & $<.0001$ & .2033 & .0435 & 4.678 & $<.0001$ \\
\hline $\mathbf{M}_{2}$ (Credibility) & --- & --- & --- & --- & --- & --- & --- & --- & -.1425 & .0490 & -2.911 & .0038 \\
\hline W (Valence) & --- & --- & --- & --- & --- & --- & --- & --- & -.4974 & .2326 & -2.138 & .0331 \\
\hline Device*Valence & --- & --- & --- & --- & --- & --- & --- & --- & .1778 & .0467 & 3.806 & .0002 \\
\hline Effort*Valence & --- & --- & --- & --- & --- & --- & --- & --- & .0809 & .0435 & 1.861 & .0635 \\
\hline Credibility*Valence & --- & --- & --- & --- & --- & --- & --- & --- & .1286 & .0490 & 2.626 & .0090 \\
\hline \multirow[t]{2}{*}{ Constant } & 4.603 & .0502 & 88.592 & $<.0001$ & 2.559 & .1969 & 12.995 & $<.0001$ & 2.408 & .2326 & 10.3513 & $<.0001$ \\
\hline & & \multicolumn{4}{|c|}{$\mathrm{R}^{2}=.1206$} & \multicolumn{3}{|c|}{$\mathrm{R}^{2}=.1143$} & \multicolumn{4}{|c|}{$\mathrm{R}^{2}=.3097$} \\
\hline & & \multicolumn{4}{|c|}{$\mathrm{F}(1,412)=56.5101, p<.0001$} & \multicolumn{3}{|c|}{$\mathrm{F}(2,411)=26.5183, p<.0001$} & \multicolumn{4}{|c|}{$\mathrm{F}(7,406)=26.0231, p<.0001$} \\
\hline
\end{tabular}




\section{Web Appendix N: Meta-Analysis}

In total, empirically this paper reported two studies using data collected from TripAdvisor and five experiments, plus one additional experiment in Web Appendix E. Collectively, these studies assessed the effects of how mobile (vs. non-mobile) reviews can influence consumers' purchase intentions for a reviewed product or service. Following recent calls (McShane and Böckenholt 2017), we conducted a single-paper meta-analysis (SPM) of the experimental studies in this paper (specifically: Studies 1B, 2A, 2B, 3, 4, and Web Appendix E). We focused on the simple effect of mobile versus non-mobile in the experimental conditions in which we expected a significant positive effect of mobile on the dependent variable. The purpose was to see how robust our results were across studies, and both standard meta-analytic techniques (Rosenthal 1984) and SPM were used (McShane and Böckenholt 2017).

Across the six experimental studies, we showed that mobile, compared to non-mobile reviews positively influenced purchase intentions. Across our studies, we found that our average effect size of mobile on purchase intentions was .30 with a standard deviation of .16 (min $=.14$, $\max =.52)$. Using standard meta-analysis techniques, effect sizes were calculated where the average weighted $\eta$ was 0.26 , and the overall relationship was significant $(\mathrm{z}=8.38, p<.001)$. Based on McShane and Böckenholt's (2017) SPM methodology, the across-study estimate of the effect of mobile on purchase intentions is .47 (95\% CI: .21 - .77), indicating that mobile, compared to non-mobile reviews, positively influenced purchase intentions since the confidence interval does not contain zero. Finally, using Rosenthal and Rosnow’s (2008) file drawer technique, which provides another way to characterize the robustness and strength of an effect, it would take an additional 150 null studies to make the overall significant finding of mobile reviews positively influencing purchase intentions become non-significant at the $5 \%$ level. 
As these analyses indicate, the effect is robust. Combined with the real-world data, the effect of the "via mobile” cue appears to be detectable. This occurs despite the mobile cue possibly not being noticed by some consumers (e.g., as noted in the paper, across our experiments, $5 \%-18 \%$ of participants failed to notice this cue based on our attention checks). We acknowledge that the cue's inherently subtle nature may be a limitation to marketers' abilities to make large-scale use of it in practice. However, given that the effect is robust and since it is found in our TripAdvisor studies, we are confident in its practical applicability if used in conjunction with other marketing techniques. 